\title{
力致发光现象及其应用研究进展
}

\author{
常 凯 ${ }^{a}$ 李倩倩*,a 李 振 $*, a, b$ \\ ( ${ }^{a}$ 武汉大学化学与分子科学学院 索维奇国际分子科学研究中心 武汉 430072) \\ ( ${ }^{b}$ 天津大学分子聚集态科学研究院 天津 300072)
}

\begin{abstract}
摘要 近年来, 力致发光作为一种独特的发光现象, 发展迅速, 在应力检测、防伪加密、新型光源、生物成像等方面展 现出巨大的应用前景. 随着人们对分子聚集态科学的关注，特别是对有机分子固态下的排列和堆积方式、分子间相互 作用等方面的深入认识，有机力致发光材料近几年发展迅速，并逐步实现多场景下的应用. 从力致发光现象与机理出 发, 讨论了有机力致发光现象与分子聚集态的关系，简要介绍了力致发光的测试表征手段、施加应力大小与力致发光 强度的关系和力致发光颜色等, 着重介绍了目前力致发光的应用, 并对力致发光材料进行了总结与展望.
\end{abstract}

关键词 力致发光; 机理; 分子聚集态; 应用

\section{Advances in Mechanoluminescence and Its Applications}

\author{
Chang, $\mathrm{Kai}^{a}$ \\ Li, Qianqian ${ }^{*, a}$ \\ Li, Zhen *,a,b \\ ( ${ }^{a}$ Sauvage Center for Molecular Sciences, College of Chemistry and Molecular Sciences, Wuhan University, Wuhan, 430072) \\ ( ${ }^{b}$ Institute of Molecular Aggregation Science, Tianjin University, Tianjin 300072)
}

\begin{abstract}
In recent years, mechanoluminescence, as a unique luminescence phenomenon, exhibited huge potential applications and rapid development in stress detection, anti-counterfeiting, encryption, light sources and bio-imaging, etc. Recently, great efforts have been made on molecular aggregation science, molecular packing and intermolecular interaction in the solid state have been deeply understood, directly promoting the development and application of mechanoluminescence and photoluminescence materials. The phenomenon and mechanism of mechanoluminescence were firstly introduced, the relationship between mechanoluminescence and aggregation behaviors of organic compounds were discussed in detail. The measurement and characterization of mechanoluminescence, the relationship between applied stress and mechanoluminescence intensity, and the color of mechanoluminescence were briefly introduced, then, the current application of mechanoluminescence was highlighted. In the end, the prospect of organic mechanoluminescence materials was afforded.

Keywords mechanoluminescence; mechanism; molecular aggregation; application
\end{abstract}

力致发光(Mechanoluminescence, ML)是一种古老 而神奇的光学现象, 最早记载于 1605 年弗朗西斯・培根 的《Advancement of Learning》一书, 块状的糖在受到刮 擦或破碎时能观察到发光 ${ }^{[1]}$. 一般而言, 力致发光指在 机械力作用下的发光现象. 机械力的形式包括但不限于 研磨、刮擦、摇动、吹气和按压等, 在超声波、红外激 光脉冲的条件下也可以产生力致发光现象 ${ }^{[2]}$. 力致发光 区别于光致发光 (Photoluminescence, PL)、电致发光 (Electroluminescence, EL)、化学发光(Chemiluminescence, CL) 和生物发光(Bioluminescence, BL) 等光发射现象
最大的特征是激发源的不同，对于力致发光而言，机械 力是激发源. 机械力主要起激发的作用, 具体的发光颜 色、延迟发光等现象与化合物自身的性质密切相关.

力致发光现象存在的尺度很广, 小到使用原子力显 微镜的探针压单个微小的颗粒 ${ }^{[3]}$, 大到岩石在地震中开 裂 ${ }^{[4]}$, 都能产生力致发光现象. 在施加的机械力从小增 大的过程中, 晶体可能会依次经历弹性形变和塑性形 变, 并最终导致晶体破裂. 按照晶体的形变与破裂可以 将力致发光分为弹性力致发光(Elasticoluminescence)、 塑性力致发光(Plasticoluminescence)和破裂力致发光

\footnotetext{
* Corresponding authors. E-mail: qianqian-alinda@163.com; lizhen@whu.edu.cn Received June 24, 2020; revised August 7, 2020; published online August 18, 2020. Dedicated to the 40th anniversary of Chinese Journal of Organic Chemistry. Project supported by the National Natural Science Foundation of China (Nos. 51673151, 21734007). 国家自然科学基金(Nos. 51673151, 21734007)资助项目.
} 


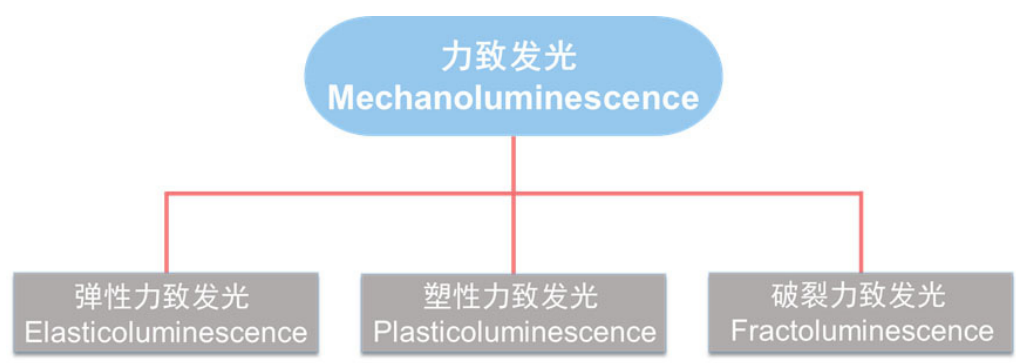

图 1 力致发光的分类

Figure 1 Classification of mechanoluminescence

(Fractoluminescence)三类 ${ }^{[5-7]}$, 如图 1 所示. 形变导致的 力致发光现象的特点是材料在力刺激的过程中没有断 裂或损坏, 因此这些材料可以在多次施加机械刺激的循 环中产生可重复的发光现象, 非常有利于实际应用, 目 前应用最广泛的力致发光材料就是基于弹性形变的材 料, 如 $\mathrm{ZnS}: \mathrm{Mn}^{2+}$ 和 $\mathrm{SrAl}_{2} \mathrm{O}_{4}: \mathrm{Eu}^{2+}$ 等 $^{[8]}$. 就破裂力致发光 而言, 晶体破碎的过程中也伴随着大量的形变, 然而破 裂与形变最大的不同是晶体破碎形成了许多高能的新 表面, 这些新的表面溅射出电子、离子、中性分子和分 子碎片, 与力致发光的产生有关 ${ }^{[9]}$. 据估计, 只有少数 固体表现出弹性和塑性力致发光, 近 $50 \%$ 的无机盐和有 机分子晶体表现为破裂力致发光 ${ }^{[10]}$. 虽然潜在的数量 巨大，但是依赖晶体破裂的特性也在一定程度上造成了 破裂力致发光在应用方面的局限.

2001 年, 唐本忠等 ${ }^{[11]}$ 提出了聚集诱导发光(Aggregation-induced Emission, AIE) 的概念, 揭示了具有扭曲 空间结构的分子在溶液中表现出微弱的荧光, 但在聚集 状态下表现出强烈的发光现象, 为设计固态下具有强烈 发射的分子提供了思路，促进了有机力致发光材料的开 发. 不同种类机械力刺激下的力致发光现象如图 2 所示. 本文首先介绍不同类型的力致发光现象及其机理
和检测方式等，重点强调力致发光的相关应用，最后对 其发展前景进行了展望. 需要指出的是, 有一类特殊的 高分子, 能在机械力的拉伸作用下导致内部化学键的断 裂而发光 ${ }^{[16-17]}$, 不在本文的讨论范围内.

\section{1 力致发光的机理}

力致发光现象已经了存在了数百年，但仍然没有公 认的理论能够解释整个物理过程. 虽然力致发光的产生 看起来相当简单, 但是对其机理的详细研究却极为困难 (因为时间太短, 很难对其变化过程进行细致观察). 目 前主要的几种机理包括晶体破裂形成的电场 ${ }^{[18]}$ 和电子 轰击 ${ }^{[9]}$ 、压电诱导载流子去俘获、压电效应诱导电致发

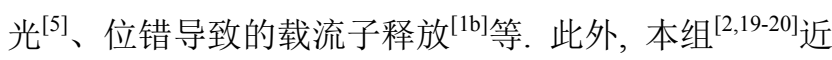
期研究表明，有机力致发光晶体中的堆积和分子间相互 作用对其 ML 性能具有非常大的影响. 由于不同类型的 ML 现象有不同的机制，下面将围绕部分普遍接受的机 理予以分类介绍(图 3).

\section{1 破裂力致发光}

Chandra 等 ${ }^{[9]}$ 提出, 破裂力致发光是由破裂过程中 新生成的带电表面所引起，其机制可能经历如下过程.
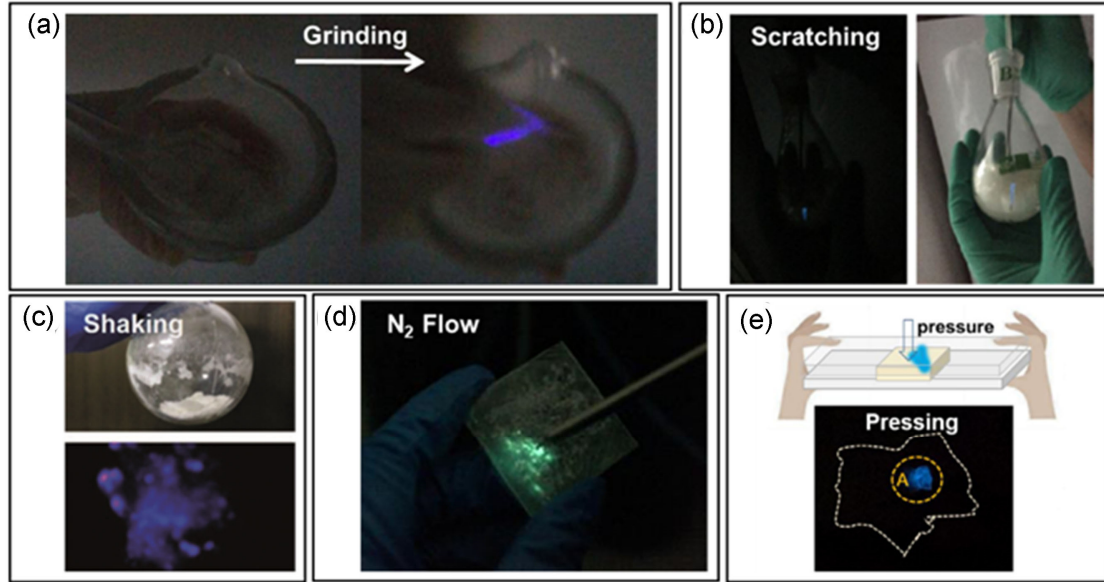

图 2 多种机械力作用下的力致发光现象

Figure 2 Classification of mechanoluminescence

(a) Grinding ${ }^{[12]}$. Reproduced with permission from Ref. [12]. Copyright 2019 John Wiley and Sons. (b) Scratching ${ }^{[13]}$. (c) Shaking ${ }^{[14]}$. (d) $\mathrm{N}_{2}$ Flow ${ }^{[14]}$. Reproduced with permission from Ref. [14]. Copyright 2018 John Wiley and Sons. (e) Pressing ${ }^{[15]}$. Reproduced with permission from Ref. [12]. Copyright 2019 John Wiley and Sons 
(a)

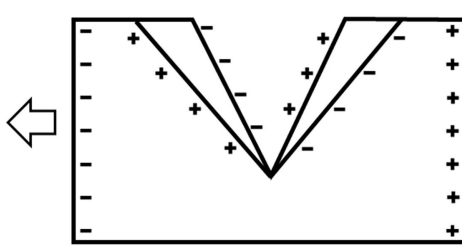

(b)

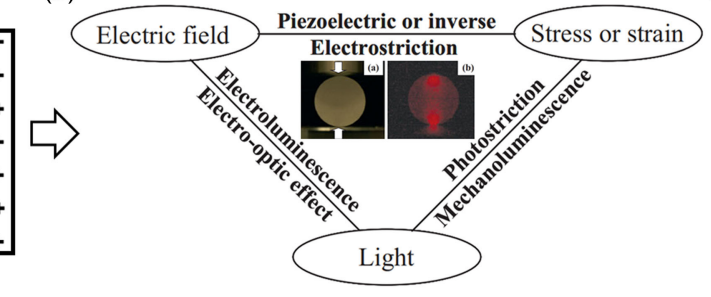

(c)

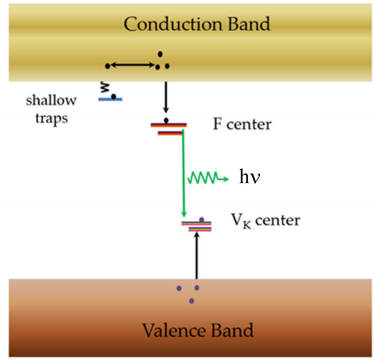

图 3 不同类型力致发光的可能机理示意图

Figure 3 Possible mechanism of different ML types

(a) The piezoelectric theory illustrating ML phenomena upon cracking (Fracto-ML). Reproduced with permission from Ref. [18]. Copyright 2004 IOP Publishing, Ltd. (b) Electro-mechano-optical interactions and related effects (Elastico-ML). Reproduced with permission from ref. [23]. Copyright 2019 John Wiley and Sons. (c) Schematic energy level diagram of colored alkali halide crystals with ML effect (Plastico-ML) ${ }^{[1 b]}$

(1)断裂过程中产生新的带电表面, 形成强的电场(图 3a). 对于非中心对称的晶体, 由于本身具有压电性, 所 以很容易在晶体破裂的过程中产生电场, 对于一些中心 对称的晶体, 产生电场的可能原因是晶体破碎时产生的 一些非中心结构和带电缺陷等. (2)裂纹表面之间产生的 强电场可通过电子轰击激发周围的气体分子或者直接 激发材料的发光中心而发光. 如果晶体没有发光中心, 此时的 ML 光谱为激发氛围中气体分子的发射光谱. 如 果晶体存在发光中心, 则 $M L$ 光谱可能是晶体的本征光 谱或者是由本征光谱与非本征光谱的叠加光谱 ${ }^{[10]}$.

本课题组等 ${ }^{[2]}$ 对以上理论进行了更进一步的讨论. 从光的产生来看, 发射是由电子从激发态跃迁到基态, 即激子的复合而产生的. 材料的力致发光可以是苂光、 磷光、激基复合物的发光. ML 更像是分子中激子 (Frenkel 和 Wannier 激子)复合的发射, 而不是阴极发光. 因此, 对于缺乏发光中心的化合物, 电场是由电子轰击 形成的, 从而产生氛围气体放电. 对于具有发光中心的 化合物, 电子轰击也会产生激子, 从而产生力致发光. 尽管在许多情况下, 力致发光与对应的光致发光并不相 似，但实际发射应考虑到分子环境、晶体中的几何结构 以及压碎点尖端的高压. 这个机制应该是对晶体中力致 发光现象更普适的解释. 由于许多非压电的晶体也具有 力致发光现象, 晶体是否具有压电性不是最关键的因 素. 但是对于压电晶体, 裂纹表面的电荷积累会导致更 强烈的电子轰击, 因此压电晶体确实更容易出现力致发 光现象.

\section{2 弹性力致发光}

稀土掺杂的铝酸盐和硅酸盐苂光粉以及过渡金属 掺杂的 II-VI 半导体苂光粉的弹性力致发光, 主要由压 电效应诱导电致发光(Piezoelectricity-induced electroluminescence)和压电诱导载流子去俘获(Piezoelectricityinduced carrier de-trapping) 导致 ${ }^{[5]}$. 大多数弹性力致发光 材料具有非中心对称结构 ${ }^{[21]}$, 具有压电特性, 但是 ML
现象同样存在于一些非压电的晶体中 ${ }^{[22]}$. 在 $\mathrm{Ba}_{1-}{ }_{-} \mathrm{Ca}_{x}$ $\mathrm{TiO}_{3}: \mathrm{Pr}^{3+}$ 压电陶瓷中, 材料的电致发光和力致发光的发 射光谱基本上一致，表明其具有共同的来源. 随后作者 通过计算发现，施加的应力足以诱导材料的电致发 光, 表明在此类材料中，压电效应和电致发光是产 生力致发光的根源 ${ }^{[23]}$.

但是，压电效应诱导的电致发光模型不能解释材料 在弱的机械应力作用下的力致发光. 如果机械力比较 弱, 压电产生的电场无法达到电致发光需要的阈值, 则 不能电致发光. 压电诱导载流子去俘获模型可以解释这 一问题. 材料首先通过光激发产生电荷载流子，电荷载 流子被材料中的陷阱捕获. 在弱应力下产生局部压电 场, 从而导致发光中心中载流子的去俘获并复合发光 ${ }^{[5]}$.

\section{3 塑性力致发光}

对于碱金属卤化物晶体, 塑性力致发光主要来源于 位错(Dislocations)部分之间的静电相互作用. 如图 3c 所 示, 经过 X-射线、 $\gamma$-射线辐照的碱金属卤化物晶体的力 致发光现象可能遵循以下步骤 ${ }^{[1 b, 24]}$ : (1)塑性形变引起位 错运动; (2)运动中的位错从具有相互作用的位错扩展区 的 F-中心(由一个或多个电子填充的阴离子空位)捕获电 子; (3) F-中心俘获的电子随位错运动, 也沿位错轴漂 移; (4)位错俘获的电子和其他空穴中心复合发光.

\section{4 有机力致发光晶体中的分子堆积和分子间相互作 用}

有机晶体在聚集态下的光物理性质与分子结构和 排列密切相关. 李振等 ${ }^{[25]} 2018$ 年提出 “Molecular Uniting Set Identified Characteristic (MUSIC)” 的理念, 强调了分子聚集态的核心作用 ${ }^{[26]}$, 可应用于光电功能 材料的多个领域 ${ }^{[27-32]}$. 早在 1976 年, Zink 等 ${ }^{[33]}$ 在研究糖 的 ML 现象时就提出, ML 不仅与晶体的大小有关, 也可 能与晶体结构和晶体堆积有关. 近年来, 越来越多的有

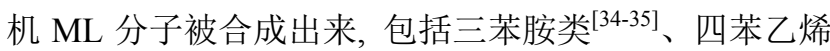
类 ${ }^{[36-38]}$ 、三苯乙烯类 ${ }^{[39]}$ 、萠类 ${ }^{[40]}$ 、咔唑类 ${ }^{[41]}$ 和吩噻嗪 
类 ${ }^{[42]}$ 等. 它们的结构变化很大, 几乎没有共同的特征, 但系统研究它们在聚集态下的堆积, 不难发现, 它们大 多采取一种构象交叉、相互锁定、分子间相互作用强的 稳定结构. 如图 4a 所示, 这种结构可以避免机械力作用 下可能发生的分子滑移而导致的能量损失, 抑制机械力 作用下的非辐射跃迁过程, 更有利于力致发光现象的产 生. 同时, 由于光致发光和力致发光在发射过程中有一 定的相似性, 强的聚集态光致发光特性对可能的力致发 光现象具有积极的作用 ${ }^{[20]}$.

但是, 分子间的堆积并不是越紧密越好. 李振等 ${ }^{[43]}$ 设计并合成了 10 种含有不同卤原子且取代位置不同的 三苯胺衍生物, 研究了分子堆积的紧密性对 ML 性能的 影响. 结果表明, 相比较而言, 松散堆积的晶体在机械 刺激下容易坍塌. 晶体中具有强分子间相互作用的紧密
堆积确实可以减少非辐射弛豫导致的能量损失, 实现明 亮的 ML. 然而, 如果分子堆积过于紧密, 晶体由于具 有强的刚性而不易破碎, 反而会导致较弱的 ML(图 4b).

\section{2 致发光的测试表征方法}

对于新制备的 ML 材料，需要采用恰当的方法对它 的 ML 性能进行表征, 包括力致发光光谱、机械刺激的 大小与发光强度的关系等. 以下将针对一些具有代表性 的测试方法进行阐述.

对于有机晶体而言, 一般不需要预处理, 可以直接 测试机械刺激导致晶体破碎的方式发光. 如图 5a 所示, 将待测试的晶体置于敞口容器中, 在黑暗环境中利用石 英管保护的光谱仪探头刮擦、研磨晶体，就能在计算机 上记录样品的力致发光光谱 ${ }^{[15,44-45]}$. (a)

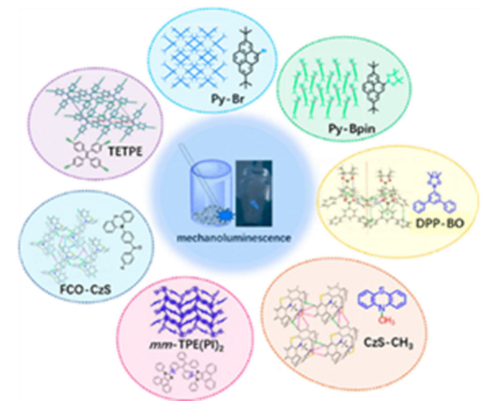

(b)

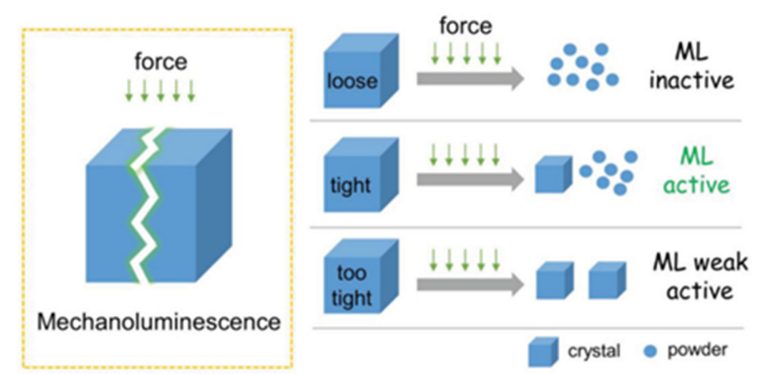

图 4 (a)各种有机力致发光材料以及它们的分子堆积方式和分子间相互作用和(b)不同分子堆积导致不同力致发光性能示意图

Figure 4 (a) Kinds of organic materials with mechanoluminescence and their molecular packing and intermolecular interactions and (b) different mechanoluminescence properties with varied packing mode in crystals

(a) Reproduced with permission from Ref. [20]. Copyright 2020 American Chemical Society. (b) Reproduced with permission from Ref. [43]. Copyright 2019 John Wiley and Sons.

(a)

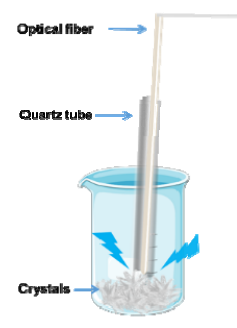

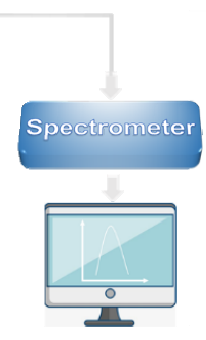

(c)

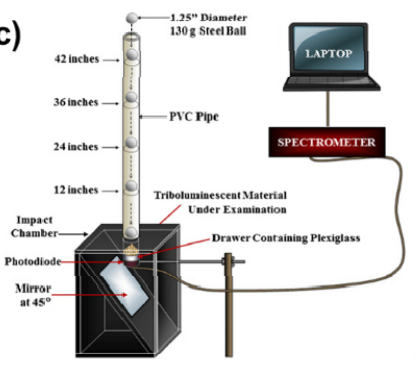

(b)

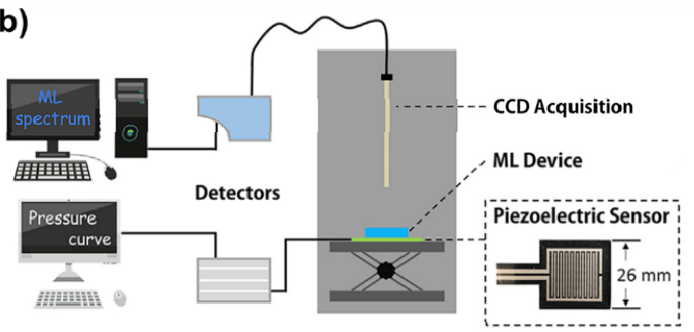

(d)

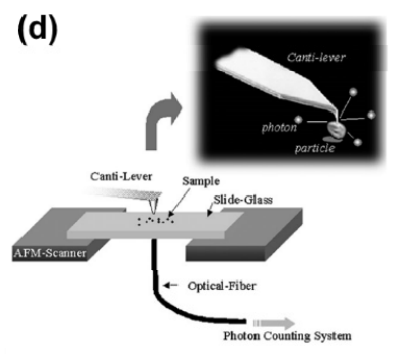

(e)

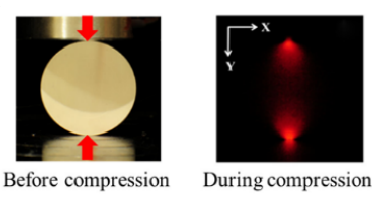

图 5 力致发光的测试表征装置的示意图

Figure 5 Schematic diagrams of ML devices for measurement and characterization

(a) ML spectra generated by simply scraping. (b) The recorder of ML spectra and strengthen of mechanical force at the same time.Reproduced with permission from Ref. [46]. Copyright 2020 Elsevier. (c) The conversion efficiency of ML detected by falling ball method. (d) ML effect of single particles by AFM. Reproduced with permission from Ref. [3]. Copyright 2006 Royal Society of Chemistry. (e) Light intensity distribution of ML composite materials under pressure. 
有机晶体的机械力大小和发光强度关系的分析测 试系统如图 $5 \mathrm{~b}$ 所示 ${ }^{[46]}$. 将一个方形压电传感器固定在 平台中部, 使得制备的 ML 器件与传感器精确重叠, 以 确保能够全面地收集机械力强度的数据. 在黑暗的环境 中进行机械力刺激时, 通过压电传感器和电荷耦合器件 (CCD, Charge-coupled Device)检测器, 同时获得机械力 强度与力致发光光谱的信息, 可建立机械力-发光强度 的关系，有利于多种功能应用的开发.

力致发光效率测试的冲击试验塔如图 5c 所示. 测 量时，首先在有机玻璃板下放置样品粉末，固定质量的 钢球从一定的高度落下并与具有 ML 性质的样品碰 撞 ${ }^{[47]}$. Hollerman 等 ${ }^{[48]}$ 利用这套装置详细比较了 27 种发 光材料的低能碰撞力致发光能量转换效率, 可开发基于 ML 的碰撞传感器. 此外, Sakai 等 ${ }^{[3]}$ 开发了一种基于原 子力显微镜(AFM)的新装置, 可以测量单个 ML 颗粒所 产生的力致发光. 对于一些 ML 颗粒与高分子复合材料 所制备的球团, 可采用万能试验机对其施加应力并记录 应变曲线, 同时利用高速照像机和光电倍增管, 可以得 到球团的 ML 图像和光电流, 进一步施加应力与光强的 关系，可获得光强分布的图像(图 5e $)^{[49]}$.

\section{3 力致发光强度与施加应力大小的关系}

确定材料产生的 ML 强度和施加应力大小的关系在 实际应用中有重要意义. 许多弹性力致发光材料的 ML 强度与外加应力在一定范围内呈线性关系, 如 $\mathrm{SrAl}_{2} \mathrm{O}_{4}: \mathrm{Eu}^{2+[50]}$ 和 CaZnOS: $\mathrm{Mn}^{2+[51]}$ 等, 但在某些条件下, ML 响应是非线性的. 外部因素方面, 非线性的可能原 因是 ML 颗粒与基体材料之间或 ML 涂层与所附着的结 构之间的应力传导不良. 内部因素方面, ML 的线性依 赖性可等同于单位时间内的应变和捕获载流子的释放

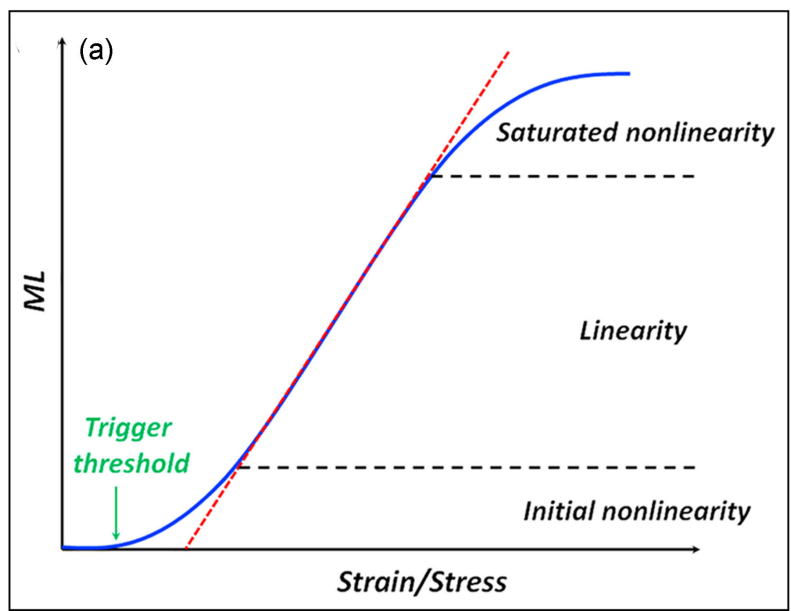

速率. 因此, 应力较小的初始阶段非线性主要是低应变 能下的载流子脱陷速率慢导致的. 非线性的第二个阶段 发生在应力更大的情况下, 是由材料中残留的数量较少 载流子的饱和效应所致 ${ }^{[5]}$ (图 6a).

对于有机晶体而言，在持续的刺激下，由于晶体断 裂, ML 强度变弱甚至消失. 这是建立 ML 强度与施加应 力的大小之间定量关系的最大障碍. 本课题组 ${ }^{[46]}$ 利用 噻吩环为自组装单元，设计并合成了 $\mathrm{tPE}-2-\mathrm{Th}$ 分子，在 持续的机械刺激下能保持良好 ML 特性, 为建立定量关 系奠定了基础. 基于此, 使用不同粒径大小的晶体制备 了 “三明治” 型的 $\mathrm{A}$ 和 $\mathrm{B}$ 两种器件, 并在不同压力下研 究其 ML 特性(图 6b). A 型器件中, 压力小于 $6 \mathrm{~N}$ 时, 随 着压力的增加 ML 强度增加较为缓慢; 当压力在 $6 \sim 14$ $\mathrm{N}$ 范围内时, $\mathrm{ML}$ 强度逐渐增大, 曲线拟合后的定量关系 近似于单指数函数; 压力大于 $14 \mathrm{~N}$ 后, 无论压力增加多 少, ML 强度稳定在 1400 单位强度左右, 将此定义为 $\mathrm{A}$ 型器件的极限值. 而对于 $\mathrm{B}$ 型器件, ML 强度与施加应力 的大小主要是线性关系, 分为压力在 $0.8 \sim 2.2 \mathrm{~N}$ 和 $2.2 \sim 6.5 \mathrm{~N}$ 范围的两段. 最后, ML 强度稳定在 110 单位 强度左右, 达到 B 型器件的极限值. 结果表明, 较大晶 体的 ML 强度更高, 较小晶体对压力的响应更敏感, 两 种器件都存在发光强度的极限值. 这是首次对基于破裂 机制的有机力致发光分子的压力与 ML 强度定量关系进 行的系统探究, 成功建立了定量关系.

\section{4 多彩的力致发光颜色}

力致发光材料体系发展到现在, 发光的波长灵活可 调, 包括了近紫外、可见光、近红外等区域 ${ }^{[52-54]}$, 能够 实现多波长的 ML 发射, 拓展了实际应用的场景. 对于 有机晶体, 发光的颜色主要与分子本身的特性以及晶体

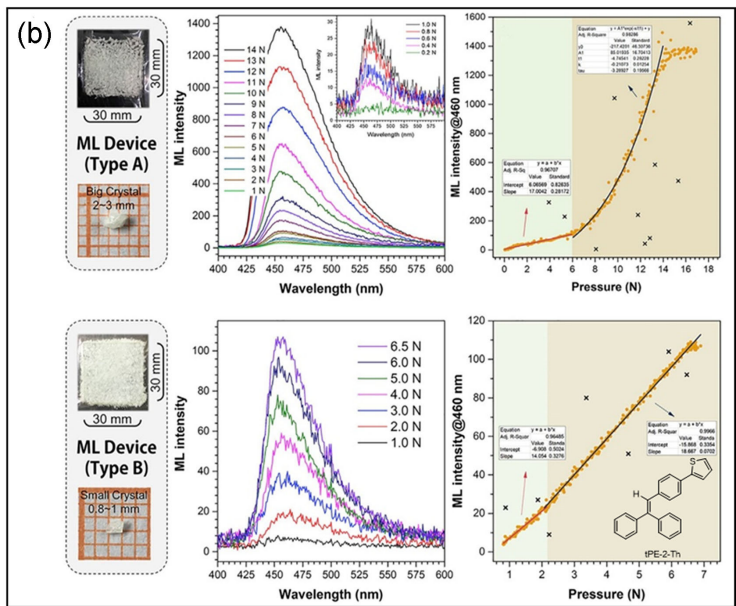

图 6 力致发光强度与施加应力大小的关系

Figure 6 Relationship between ML intensity and stress

(a) Based on Elasticoluminescence materials. Reproduced with permission from Ref. [5]. Copyright 2019 Elsevier. (b) Based on ML device of tPE-2-Th. Reproduced with permission from Ref. [46]. Copyright 2020 Elsevier. 
的堆积密切相关. 相同分子的不同堆积(同质多晶)也会 导致不同颜色的 ML 发射 ${ }^{[55]}$. 此外, 可以对具有 ML 性 质的分子进行掺杂, 通过苂光共振能量转移实现客体的 发光. 比如基于咔唑的有机分子 $\mathrm{NPC}^{[56]}$ (图 7a), 力致发 光的最大发射波长在 $420 \mathrm{~nm}$ 左右, 分别掺杂质量分数 为 4\% 5\%的客体分子; 绿色发光的 PPO、黄色发光的 DPPC7、橙色发光的 DPPC4 以及红色发光的 DPPPT, 可 以分别得到绿色、黄色、橙色、红色的 ML 发射, 如图 $7 b$ 所示.

力致发光的颜色还与分子的构象有关. 2018 年, 本 课题组 ${ }^{[57]}$ 发现有机分子 FCO-CzS 在力刺激下的构象变 化能导致发光颜色的动态变化(图 7c). 晶体分析和理论 计算表明, 晶体中呈蓝光发射的准垂直构象的分子在连 续机械刺激下被破坏, 转变为黄光发射的准平行构象的 分子, 从而导致发光颜色从蓝光到白光再到黄光的变 化. 还有些分子在机械力的作用下存在苂光、磷光的双发 射, 从而导致动态的颜色变化 ${ }^{[58]}$. 以 BrFlu-CBr 为例 ${ }^{[59]}$, 晶体在紫外光或机械刺激下均表现出苂光一磷光双重发 射. 在长时间的机械刺激下, 由于晶体结构的破坏, BrFlu-CBr 的 ML 发射由蓝绿色变为蓝色, 停止机械刺激 后观察到偏绿的白色磷光. 这是首次通过调节纯有机化 合物中的磷光强度实现摩擦发光多色转换. 单晶分析和 理论计算表明, 强烈的 $\mathrm{Br} \cdots \mathrm{Br}$ 相互作用会促进自旋轨道 偶合和隙间窝越, 对这种独特性质的产生至关重要.

对于无机材料, 调控力致发光颜色的通常方法有
用不同的发光离子掺杂磷光体、替换晶体中的主离子, 能量转移到更红移的发光中心发光以及调整施加应力 的条件等 ${ }^{[5]}$. 图 7e 展示了由两种不同的 ML 材料和聚二 甲基硅氧烷(PDMS)基质组成的复合膜对 $\mathrm{ML}$ 颜色的调 节, 通过调节 $\mathrm{ZnS}: \mathrm{Cu}, \mathrm{Mn}$ 和 $\mathrm{ZnS}: \mathrm{Cu}$ 的混合比例, 在同 一块薄膜上实现了机械力刺激下的黄色、橙色和绿色的 发光, 复合膜在 CIE 色坐标中呈现出线性组合的趋势 ${ }^{[60]}$.

\section{5 力致发光的应用}

ML 材料在各种形式机械应力作用下都能发光，常 见的有研磨、刮擦、摇动、气流、按压和超声波等. 这 种相对容易的产生方式使力致发光的应用场景非常广 泛，包括医疗保健、损伤检测、新型光源、防伪加密、 应力传感和可穿戴设备等方面, 均展现出巨大的应用前 景(图 8).

弹性力致发光材料制成的苂光粉颗粒, 在应力施加 过程中并没有被完全破坏，往往可以通过紫外光照再充 电而反复使用, 因此, 可以将 ML 苂光粉嵌入一些高分 子基体材料中制备成复合膜，对实际应用带来了很大的 便利 ${ }^{[61]}$. 而大多数破裂力致发光材料因为在机械力的 刺激下伴随着晶体破裂，在持续的机械力作用下发光会 逐渐减弱甚至消失，可使用的次数和时间有限. 当然, 有一些熔点较低的材料可以通过加热重结晶的方式恢 复其力致发光性能 ${ }^{[14,39]}$, 但这种操作与简单的紫外光照 射相比较为繁琐. 此外, 如上文提到的 tPE-2-Th, 由于
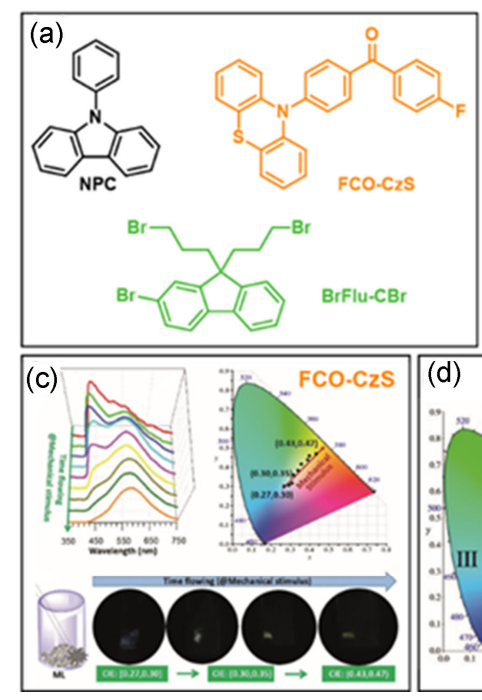
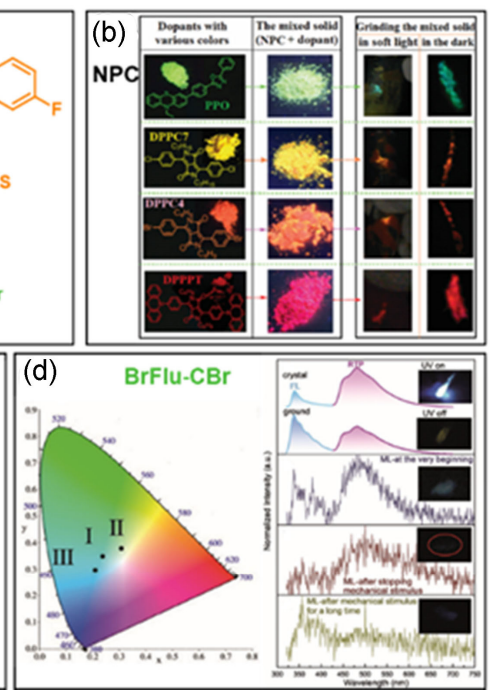

BrFlu-CBr

图 7 多彩的力致发光

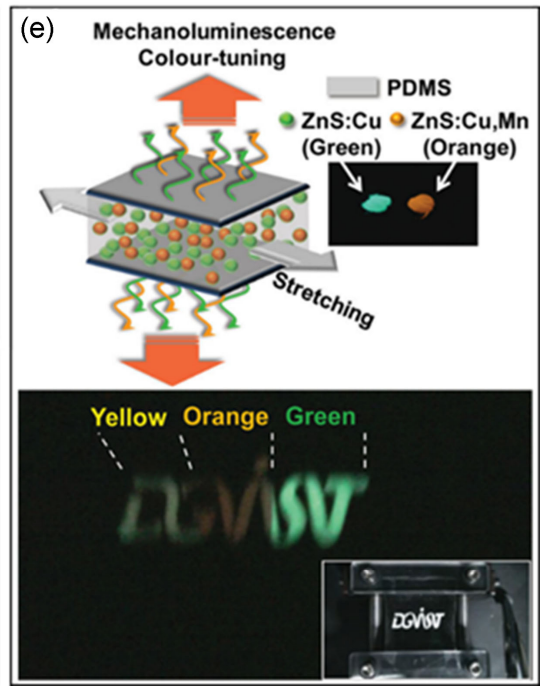

Figure 7 Multicolored ML effect

(a) Molecular structures of NPC, FCO-CZs and BrFlu-CBr. (b) Multicolored luminescence based on NPC doped with different organic molecules. Reproduced with permission from Ref. [56]. Copyright 2018 Royal Society of Chemistry. (c) Dynamic ML color of FCO-CzS with the changeable molecular conformations under mechanical stimulation. Reproduced with permission from Ref. [57]. Copyright 2018 John Wiley and Sons. (d) Dynamic ML of BrFlu-CBr with the changeable dual-emission of fluorescence and phosphorescence. Reproduced with permission from Ref. [59]. Copyright 2018 John Wiley and Sons. (E) Multicolored ML effect by mixing two kinds of elastic materials with different ML colors. Reproduced with permission from Ref. [60]. Copyright 2013 John Wiley and Sons. 


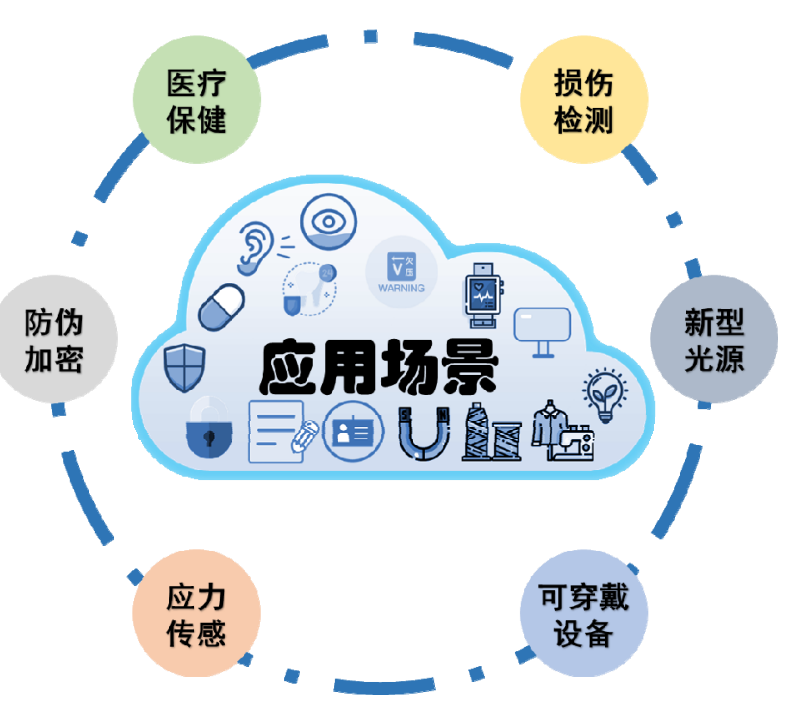

图 8 力致发光的应用场景

Figure 8 Application scenarios of mechanoluminescence

其在较长时间下的机械刺激下仍能显示出明亮的发光, 也可以在 ML 器件中稳定工作更长时间 ${ }^{[46]}$.

\section{1 医疗保健}

近年来, 随着人们对自身健康关注度的提高, 各种 健康监测传感器热销市场, 力致发光材料在此方面拥有 巨大的应用潜力.

基于 tPE-2-Th 分子制备的器件 [46], 利用力致发光强 度和压力之间的定量关系, 构建了一个简单的数据模 型, 通过设定的阈值来区分 ML 信号. 所有阈值都可以 根据不同的用户或条件重新定义. 如图 9a 所示, 当外力 分别小于 $2.0 \mathrm{~N}$ 、大于 2.0 但小于 $10.0 \mathrm{~N}$ 、大于 $10.0 \mathrm{~N}$ 时, 均有相应的语音警告. 这种器件可以较为容易地安 装在人体容易受外力损伤的部位, 如肘部、肩部、脊柱 和膝盖等, 通过发出警告有效地防止外力对关节造成的
可能损害. 除了外部应力的响应外, 这种 ML 器件还可 以对不同心率下的心跳压力产生相应的 ML 信号，实现 心率的检测. 如图 $9 \mathrm{~b}$ 所示, 心率低于 120 次 $/ \mathrm{min}$ 时几 乎没有 $\mathrm{ML}$ 信号; 当心率升至 150 次 $/ \mathrm{min}$ 时, ML 强度 变强, 但仍很低; 直到心率高于 180 次 $/ \mathrm{min}, \mathrm{ML}$ 强度会 高于用户定义的阈值，设定的程序会发出警告.

在人体的一些组织器官层面, ML 材料也具有较大 的应用潜力. 2018 年, Kim 等 ${ }^{[62]}$ 利用 ML 材料模拟人耳 蜗基底膜的功能, 利用非接触式图像传感器对具有频率 选择性的 ML 复合膜进行可视化测量. 如图 10a 所示, 与传统的悬臂梁阵列不同, 由 $\mathrm{ZnS}: \mathrm{Cu}$-聚二甲基硅氧烷 复合材料制成的 ML 基底膜能有效地显示行波 (Travelling-wave) 最大振幅位置对应变速率的分布, 具 有制作人造耳蜗的潜力. 2019 年, Kim 等 ${ }^{[63]}$ 还基于 $\mathrm{ZnS}: \mathrm{Cu}$-聚二甲基硅氧烷(PDMS), 制备了一种机械力驱 动的复合材料, 用于产生光信号 (图 10b). 与人眼的角膜 行为相似, 附着在球壳结构上的软复合材料在充气时也 会发生向内和向外的变形, 从而在 ML 软复合材料中产 生双光信号，在眼压监测方面具有应用潜力. 刘斌等 ${ }^{[64]}$ 提出了一种基于 ML 材料的判断人工牙咬合检查的新方 法. 作者选择稀土掺杂的铝酸锶 $\left(\mathrm{SrAl}_{2} \mathrm{O}_{4}: \mathrm{Eu}^{2+}, \mathrm{Dy}^{3+}\right)$ 作 为 ML 材料, 与市售的树脂假牙复合, 在保持生物相容 性的同时改善了假牙的力学性能. 结果表明, 基于 $\mathrm{ML}$ 的假牙咬合检查是可行的，从假牙模型中发出明亮、灵 敏的 ML 可以指导临床医生更精确地调整咬合面.

最近，洪国松等 ${ }^{[65]}$ 开发了一种基于力致发光的光 遗传学调节方式，即利用力致发光控制光响应离子通道 基因修饰的细胞. 由于可见光对组织的穿透能力有限, 活体光遗传学调节通常需要有创性开乑术和乑内植入 光纤. 当力致发光的纳米颗粒通过完整的头皮和头骨且
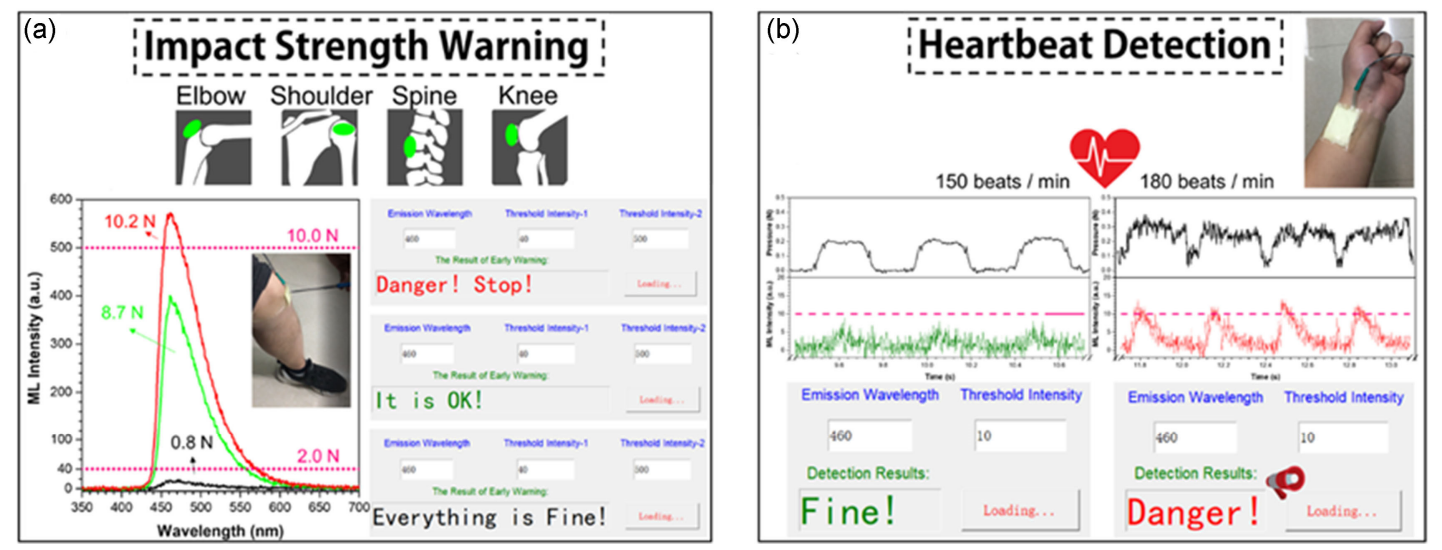

图 9 基于 tPE-2-Th 制备的 ML 器件对(a)关节碰撞预警和(b)心跳监测

Figure 9 ML devices based on tPE-2-Th for (a) impact strength warning and (b) heartbeat detection Reproduced with permission from Ref. [46]. Copyright 2020 Elsevier. 

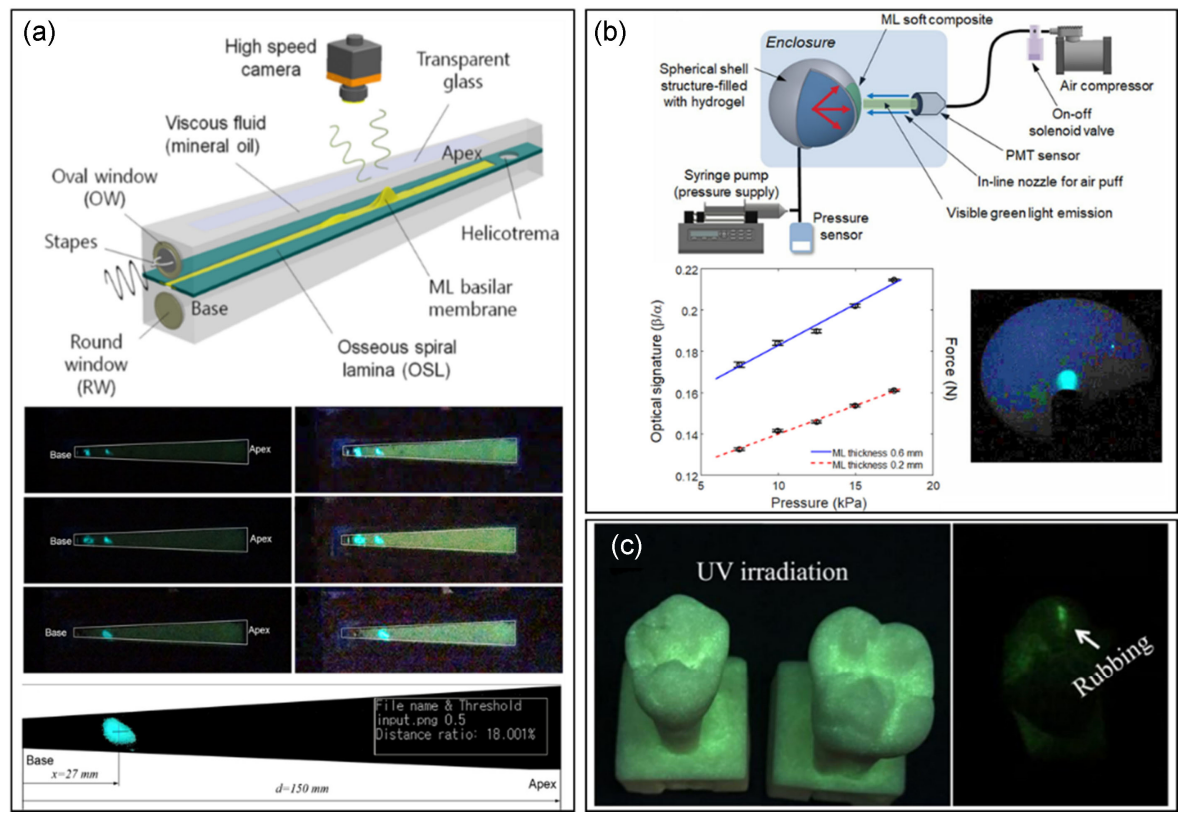

图 10 力致发光在组织器官方面的潜在应用

Figure 10 Potential applications of mechanoluminescence in tissues and organs

(a) Cochlear implant. (b) Intraocular pressure monitoring. (c) Teeth occlusion examination. Reproduced with permission from Ref. [64]. Copyright 2018 Elsevier.

被脑渗透聚焦超声触发时，可以作为大脑的局部光源. 这种方法在没有头皮切口、开硕手术或大脑植入的情况 下，在大脑中提供微创的光基因神经调节.

如图 11a所示, ML 纳米粒可以通过静脉注射进入血 液循环, 在循环过程中由浅表血管中的 $400 \mathrm{~nm}$ 紫外光 照射充能, 并由聚焦超声(Focused ultrasound, FUS)开启, 在完整的大脑中重复发射 $470 \mathrm{~nm}$ 光进行光化学刺激. ML 颗粒强烈的发光, 会对视神经的光敏通道蛋白 -2 (ChR2)进行刺激(图 11b). 在体外对此过程进行成功的 模拟之后，作者对小鼠进行了活体实验，实验结果表明， 在血液中注射 ZnS:Ag, Co@ZnS 纳米粒子后, $\mathrm{ChR} 2$ 表达 的 Thy1-ChR2 YFP 小鼠出现明显的后肢运动, 与聚焦 超声刺激同步. 在相同的刺激下, 相同的动物在注射纳 米颗粒之前没有表现出任何后肢运动. 大脑中没有 ChR2 表达的野生型小鼠, 无论血液循环中是否存在 ML 纳米颗粒, 都没有后肢运动(图 11d). 总而言之, 与 传统的光纤植入的光遗传学方法不同, 可以通过血液循 环系统传输纳米级的发光材料, 并可以通过超声波在任 何时间和在大脑中所需的位置打开和关闭它们, 进行光 遗传学的调控. 这个例子也为 $\mathrm{ML}$ 的活体应用提供了新 的可能性.

\section{2 损伤检测}

对应力高灵敏响应的 ML 材料可以用于结构的损伤 检测 ${ }^{[66]}$. 通常, 将 ML-高分子复合层或者 ML 涂层与目 标结构紧密结合, 再采用适当的方式探测发光信号及分
布, 从而推算出结构承受的应力 ${ }^{[67]}$.

王赵锋等 ${ }^{[68]}$ 开发了一种利用 ML 复合层进行磨损 预警的方法(图 12A). 将 $\mathrm{SrAl}_{2} \mathrm{O}_{4}: \mathrm{Eu}^{2+}, \mathrm{Dy}^{3+}$ (SAOED)粉 末与典型的石墨/环氧树脂固体润滑材料复合，赋予复 合材料强力致发光性能的同时还保持了良好的摩擦学 性能，以此制备了双层结构的固体润滑材料，顶层为石 墨/环氧树脂的润滑层, 底层为 $\mathrm{SAOED/}$ /石墨/环氧的预 警层，实现了磨损过程中的磨损失效预警功能. 该方法 可推广到各种固体润滑材料中, 具有广泛的工程应用前 景.

徐超男等 ${ }^{[5,69]}$ 报道了一种基于 ML 成像的方法, 可 以简单有效地对使用中桥梁的结构进行长期监测. 将含 有 $\mathrm{SrAl}_{2} \mathrm{O}_{4}: \mathrm{Eu}^{2+}$ 的 $\mathrm{ML}$ 复合膜附着在桥梁的可见裂缝上, 当车辆通过有缺陷的大梁时, 裂纹处受到的应力使 $\mathrm{ML}$ 膜发光，并通过高灵敏摄像机实时记录下来，处理图像 信息可以得到裂纹的位置和轮廓以及载荷的应力分布 等信息.

结构中不可见的缺陷常通过 $\mathrm{X}$ 射线和超声波来探 测, 但并不能得出缺陷处的应力分布和变化的相关信 息. 徐超男等 ${ }^{[5,69]}$ 利用 $M L$ 复合材料成像技术来检测结 构中的缺陷，并给出了缺陷周围的应力分布. 如图 $12 \mathrm{C}$ 所示，在背面钻有三个小孔(正面不可见)的金属板正面 附着含 $\mathrm{SrAl}_{2} \mathrm{O}_{4}$ : $\mathrm{Eu}^{2+}$ 颗粒的聚合物膜, 在对金属板施加 拉力期间记录 ML 图像. 拉伸期间金属板 ML 发光强度 的伪彩色 $3 \mathrm{D}$ 图像展示了对应于三个钻孔位置的 ML 信 
(a)

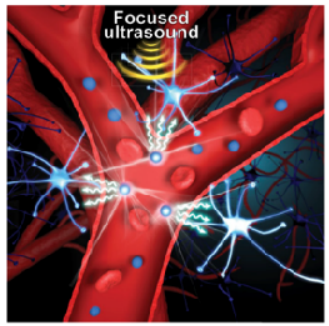

(c)

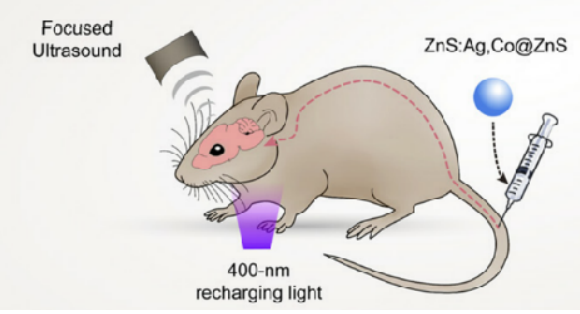

Valence band (b)

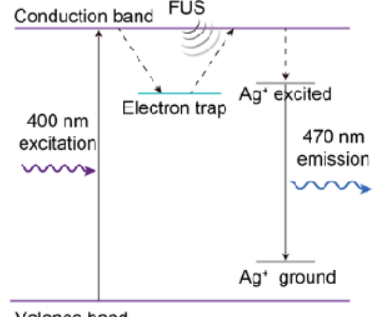

图 11 基于力致发光的光遗传学调节方式

Figure 11 Photogenetic regulation based on mechanoluminescence

(a, b) Schematic diagrams of photogenetic regulation. (c) Schematic diagram of mice in vivo experiment. (d) Comparative experiment of leg swing in mice.

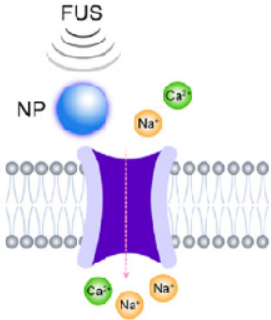

wT
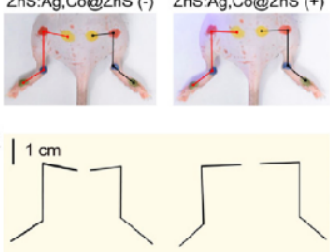

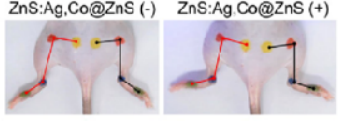

$\sqrt[1]{1 \mathrm{~cm}}]$ (d) Thy1-ChR2-YFP

\section{(A)}
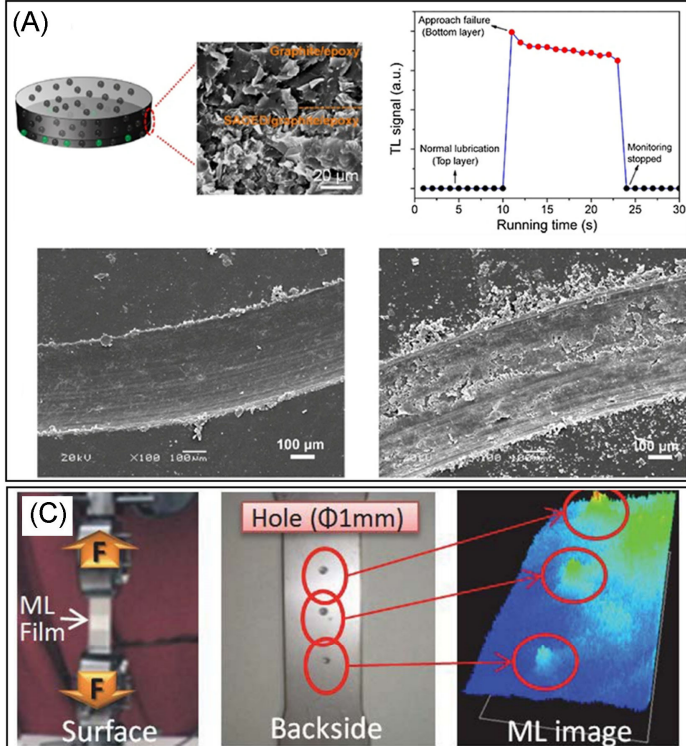

$100 \mu \mathrm{m}$
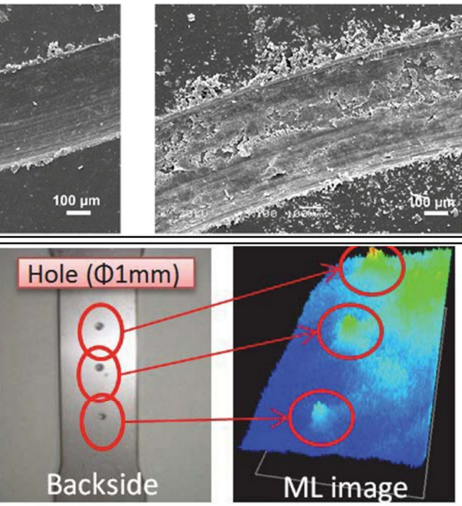

(B) (a)

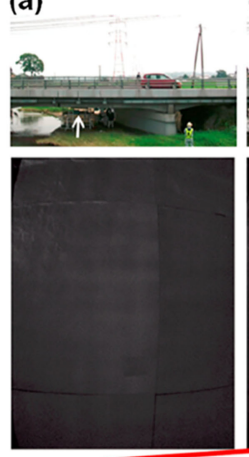

(b)

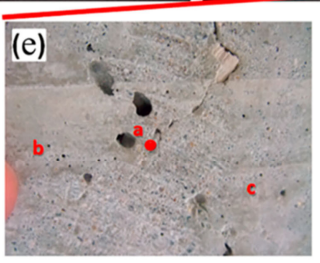

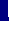


间的连接区而发出 ML. 作者还制作了两种带有 “ML” 标志的风动图案板, 并使用绿色和白色来提高能见度. 调节风速可以线性增加其亮度, 使用不同颜色的 ML 颗 粒进行掺杂也可以产生不同颜色的风驱动力致发光器 件. 但与商用照明相比, 亮度明显较弱, 对风强的要求 很苛刻, 在自然界很难实现. 因此, 开发发光强度更强, 所需应力更小的 ML 材料是解决此类问题的关键.

郝建华等 ${ }^{[74]}$ 提出了一种结合变化磁场和力致发光 现象的磁致发光(Magnetic-induced Luminescence, MIL) 的策略, 由金属离子掺杂的 ZnS-PDMS 和 Fe-Ni-Co 合 金-PDMS 的复合棒状材料实现(图 13C). 室温下, 可以 在随时间变化且低至 $\mathrm{H}_{\mathrm{rms}} \approx 3.5 \mathrm{kOe}$ 的磁场控制下, 对 制备的 MIL 器件的发光进行可逆和动态的调节. 与目 前大部分电驱动的商用显示器不同, 作为光源的 MIL 器件是由磁场驱动的, 这为特定情况下使用的显示器和 固态照明设计提供了一种新的视角和可能性.

还有一些工作将力致发光与光伏效应结合，探索了 一些光电转化的可能应用. 总体而言, 目前力致发光材 料的强度比较弱, 导致其实际应用受限.

徐超男等 ${ }^{[75]}$ 分别选择 $\mathrm{SrAl}_{2} \mathrm{O}_{4}: \mathrm{Eu}^{2+}$ 的高分子复合材 料和商用硅太阳电池作为光源和光电转换装置, 制备了 新型 ML 驱动的电池系统(图 14A). 通过施加应力, 成功 地观察到了相应的光电流产生. 随着机械应力的增加, 可以观察到光电流强度增加. 对施加应力、力致发光、 光电流随时间的变化曲线进行了详细研究, 他们认为 ML 材料可以充当太阳能电池的光源, 并且此电池系统 中产生的光电流特性也反映了力致发光的特性. 但是, 这种体系产生的光电流都非常小, 仅为几十到几百纳 安, 据作者估计, 此系统的转换效率可能小于 $1 \% \sim 2 \%$.
Magdassi 等 ${ }^{[76]}$ 报道了通过一步写入技术实现的全 打印 3D 力致发光器件, 并将风驱动的 ML 器件与钙钛 矿太阳能电池联用, 测试了输出电压和功率(图 14B). 打 印墨水由 PDMS、过渡金属离子掺杂 $\mathrm{ZnS}$ 颗粒和铂固化 缓凝剂组成，制作了具有复杂结构的三维力致发光体， 其中发光由拉伸或风吹产生. 绿色的 ML 发射与钙钛矿 材料的吸收相匹配, 因此, 通过将印刷器件与钙钛矿基 太阳能电池结合, 可以将黑暗中的风能转换为电能. 随 着氮气压力的增加, 钙钛矿太阳能电池输出的电压和功 率呈现出增加的趋势. 与上一个例子情况类似, 输出的 功率较低, 在 $400 \mathrm{kPa}$ 的氮气压力下输出功率仍在 $\mathrm{nW}$ 级 别.

$\mathrm{Ryu}$ 等 ${ }^{[77]}$ 提出了一种基于 $\mathrm{ZnS}: \mathrm{Cu}$ 的力致发光层和 聚 3-己基噻吩(P3HT, 作为光活性层)太阳能电池的多层 自供电应变传感器, 具体结构如图 14C 所示. 自供电应 变传感器的一个功能层是 $\mathrm{ZnS}: \mathrm{Cu}$ 的弹性复合材料, 它 在力的作用下发光. 另一个功能层是 P3HT 薄膜, 它在 光照下产生直流电, 其大小随应变的变化而变化. 这种 结构对传统太阳能电池的结构进行了改变, 直接使用力 致发光层作为基底. 比较可惜的是, 本文中作者只研究 了 $\mathrm{ZnS}: \mathrm{Cu}$ 复合材膜在循环拉伸应变下的 $\mathrm{ML}$ 发光特性 以及 $\mathrm{P} 3 \mathrm{HT}$ 基薄膜在 $0 \% \sim 2 \%$ 拉伸应变下的光吸收特性, 并没有对此类传感器的应用方面进行实验.

\section{4 可穿戴设备}

可穿戴设备的出现促进了显示技术、传感、电子、 能量收集和存储等领域的发展 ${ }^{[78-79]}$. 发光器件作为一种 代表性的显示单元, 寻找既灵活又可伸缩的发光器件具 有重要意义 ${ }^{[80-81]}$. 基于这些问题, 科学家们开发了多种
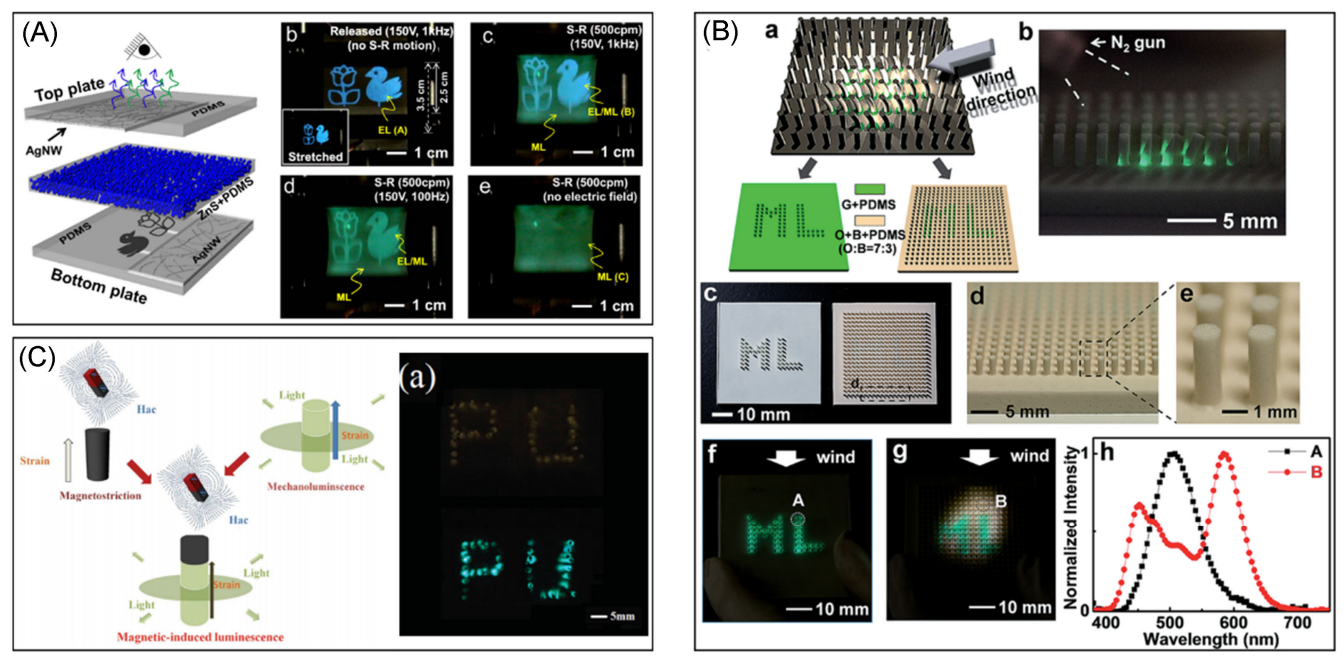

图 13 基于力致发光的新型光源

Figure 13 New light sources based on mechanoluminescence (A) ML-EL dual-emission. Reproduced with permission from Ref. [68]. Copyright 2016 Elsevier. (B) Wind-driven display. (C) Magnetic-induced luminescence. Reproduced with permission from Ref. [74]. Copyright 2015 John Wiley and Sons. 
基于力致发光的可穿戴设备.

$\mathrm{Kim}$ 等 ${ }^{[82]}$ 报道了一种基于 $\mathrm{ZnS}: \mathrm{Cu}$ 的运动驱动的发 光织物器件, 织物结构为 $\mathrm{ZnS}: \mathrm{Cu}$ 和 PDMS 的复合纤维 (图 15A). 研究表明, $\mathrm{ZnS}: \mathrm{Cu}$ 和 PDMS 的复合材料发光 器件在一个拉伸周期内可以发射两次, 并且连续的光可 以通过各种运动发射. 彭慧胜等 ${ }^{[83]}$ 使用涂覆法, 制备了 一种基于过渡金属掺杂的 $\mathrm{ZnS}$ 和 PDMS 复合物的高拉 伸柔性力致伸缩纤维. 所得到的复合纤维在拉伸和释放 时发出强度可调的柔和光. 此外, 即使在 10000 次拉伸 和释放循环后, 其结构和光学性能仍保持良好. 通过不
同离子的掺杂以及不同的颜色组合，复合纤维的颜色也 可以调整为绿色、黄色或橙色，这些颜色甚至可以组合 在一根纤维中. 最后, 采用这种方法制备了具有不同显 示效果的机械致发光织物(图 15B).

除了可穿戴的织物外，支春義等 ${ }^{[84]}$ 还报道了一种 可穿戴的智能皮肤(图 15C). 智能皮肤采用类似 “三明 治”的多层结构，自下而上的成分层顺序为: 以 Ecoflex 弹性体层为基底, 中间以含 $\mathrm{NaCl}$ 的 $\mathrm{PAA}$ 水凝胶为离子 导体，以 Ecoflex-ZnS 复合层为 ML 层. 这种结构的智能 皮肤可以实现能量采集、触摸传感和外部视觉等功能.
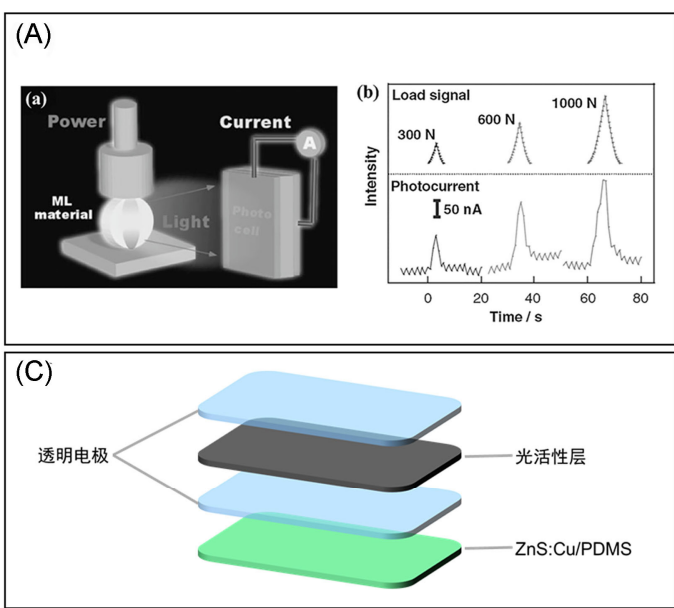

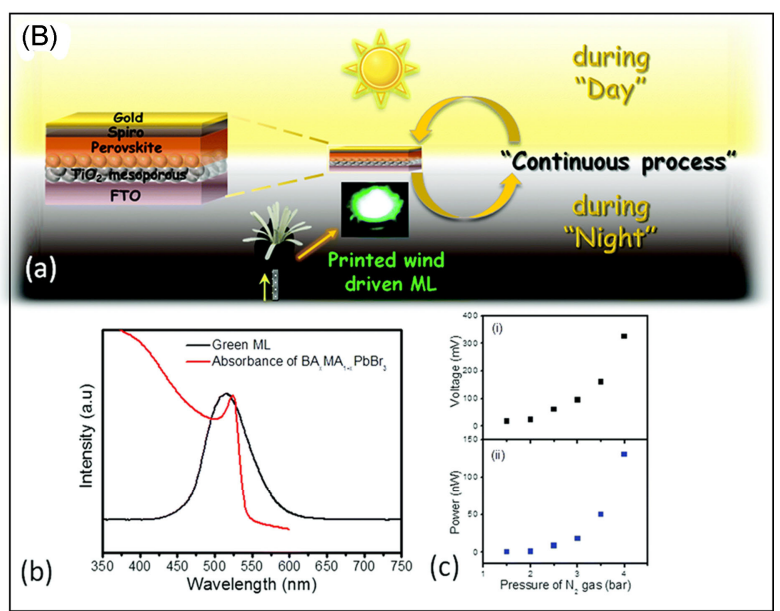

图 14 力致发光与光伏效应结合的应用

Figure 14 Applications based on the combination of mechanoluminescence and photovoltaic effect

(A) Solar cell systems driven by ML. Reproduced with permission from Ref. [5]. Copyright 2019 Elsevier. (B) Wind power generation device driven by ML. Reproduced with permission from Ref. [75]. Copyright 2018 Royal Society of Chemistry. (C) Devices integrated by ML layer and solar cells.
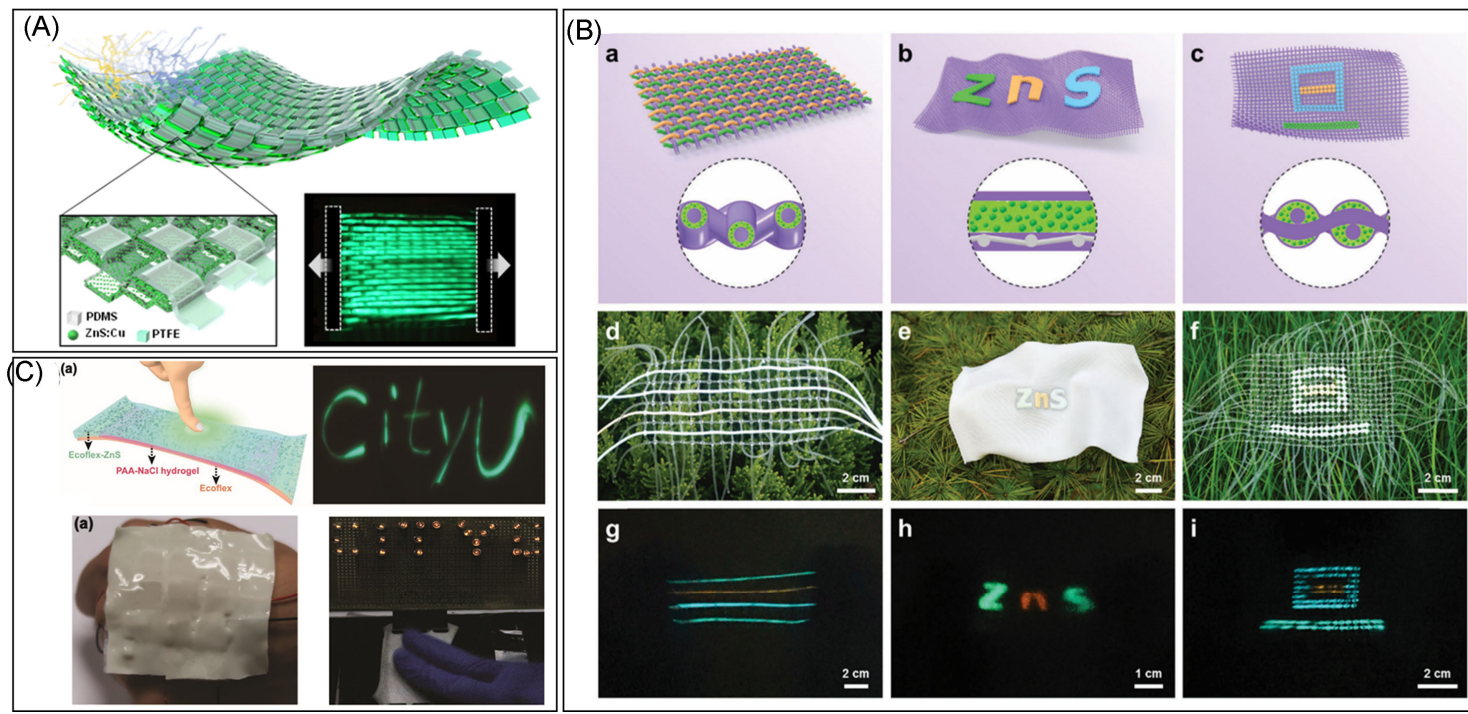

图 15 基于力致发光的可穿戴设备

Figure 15 Wearable device based on mechanoluminescence materials

(A, B) Fabric devices based on ML materials. Reproduced with permission from Ref. [82]. Copyright 2019 American Chemical Society. Reproduced with permission from Ref. [83]. Copyright 2017 Royal Society of Chemistry. (C) Intelligent skin based on ML materials. Reproduced with permission from Ref. [84]. Copyright 2019 John Wiley and Sons. 
首先, 智能皮肤可以作为摩擦电纳米发电机发挥作用, 并在 10000 个连续接触一分离循环中提供 $180 \mathrm{~V}$ 的输出 峰值电压和 $625 \mu \mathrm{W} \cdot \mathrm{cm}^{-2}$ 的功率密度, 具有极好的循环 稳定性. 其次, 智能皮肤可以检测到 $0.58 \mathrm{kPa}$ 的压力极 限, 其灵敏度为 $0.23 \mathrm{kPa}^{-1}$, 并能实现位置检测. 最后, 智能皮肤具有发光响应, 以便能够可视化所施加力的大 小和位置. 值得注意的是, 即使在设备承受 700\%的高 应变时, 已开发的智能皮肤的功能也不会降低, 显示出 强大的承受能力.

\section{5 应力传感}

随着电子技术的发展, 对应力传感器的灵敏度、准 确性、传感范围、空间分辨率和功耗的要求进一步提高. 相比于电阻、电容、压电式的应力传感器, 力致发光是 应力传感器的一种全新响应方式, 并且已经具有了较为 成功的应用 ${ }^{[85-86]}$

潘曹峰等 ${ }^{[87]}$ 介绍了一种以 $\mathrm{ZnS}: \mathrm{Mn}$ 为 $\mathrm{ML}$ 颗粒的压 力传感矩阵, 如图 16A 所示, 该器件可在 $0.6 \sim 50 \mathrm{MPa}$ 范围内利用自发光进行单点动态压力记录和二维平面 压力映射. 这种器件具有小于 $10 \mathrm{~ms}$ 的快速响应时间、 $254 \mathrm{dpi}$ 的高空间分辨率以及经过数千次测试循环后仍 稳定可重复的优异性能. 通过记录手写签名和签名习 惯, 充分记录签名过程中每个像素点的动态压力分布和 签名速度，从而实现对不同签名习惯的分析. 这种矩阵 器件可能在实时压力映射、智能传感器网络、高级安全 系统和人机界面方面有着潜在的应用.

为克服应力传感器灵敏度较低、检测限较高和在生 物体系适用性不佳的问题, Park 等 ${ }^{[88]}$ 开发了具有 $\mathrm{ZnS}: \mathrm{Cu}$
力致发光层和空气电介质的压敏 $\mathrm{MoS}_{2}$ 晶体管的集成有 源矩阵阵列, 可对从走路时脚落地的压力到单个细胞运 动产生的压力进行广泛检测 $(70 \mathrm{~Pa} \sim 5 \mathrm{MPa})$. 在整个压 力范围内, $\mathrm{ML}$ 材料和空气介质的加入可以显著提高其 灵敏度. 这种具有空气介质结构的压敏场效应晶体管具 有低滞后和高跨导的特点，从而提高传感器的可靠性和 响应时间. 此外, 该器件的空间分辨率被提高到足以分 析单个心肌细胞内压力分布，可以捕捉到心肌细胞的运 动(图 16B). 这种传感器阵列将有助于监测生物学中的 多种运动, 将来可以应用于肌肉、关节和软骨中，以及 心脏和血管系统相关的各种生物医学电子技术中. 此 外, 还可以有效地用于机械生物学中细胞水平的研究.

\section{6 防伪加密}

目前，光致发光、上转换发光和长余辉发光是用于 防伪和信息安全的三种典型模式 ${ }^{[89]}$. 力致发光作为一 种独特的刺激响应形式，非常适合在特定的场合用于信 息加密及防伪, 并可以与其他防伪方式结合使用达到更 好的效果.

上文提到的基于破裂力致发光分子 $\mathrm{tPE}-\mathrm{Th}$ 设计的

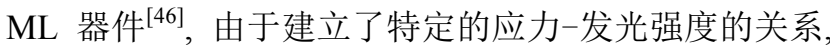
也可以应用于加密领域(图 17A). 通过人为设定一个 ML 强度的阈值, 当 ML 信号强度低于此阈值时, 记录 为 “ 0 ”，否则记录为 “ 1 ”，与二进制数据类似. 然后在 计算机上编辑一个简单的翻译程序来分析和转换 ML 谱 图的数据. 参数发射波长和阈值强度可根据需要设定任 意值. 例如设定阈值为 $5.5 \mathrm{~N}$, 则在 $3.2 、 3.8 、 2.8 、 0.7$ 和 $3.5 \mathrm{~N}$ 的不同压力下记录的 $\mathrm{ML}$ 光谱可以转换为
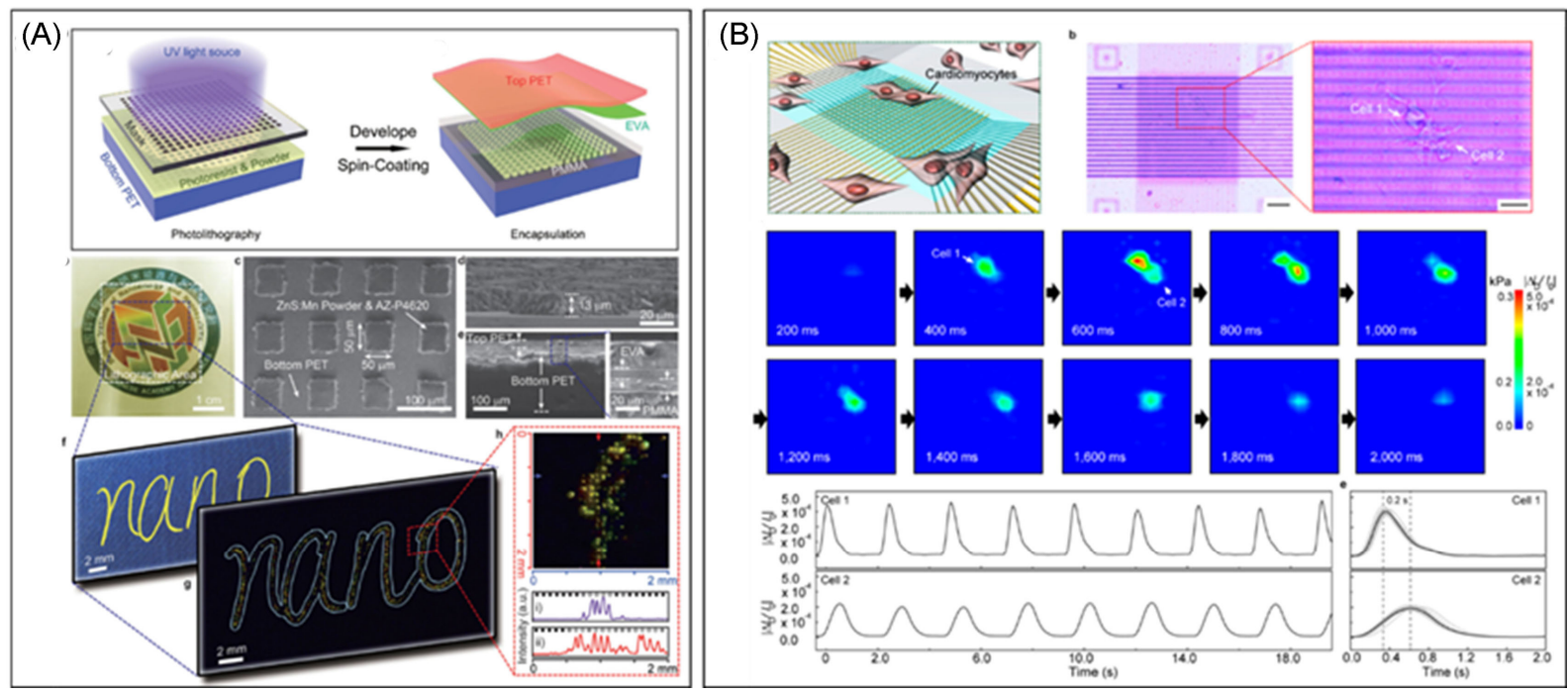

图 16 力致发光在应力传感方面的应用

Figure 16 Application of mechanoluminescence materials in stress sensing

(A) Pressure sensing matrix. Reproduced with permission from Ref. [87]. Copyright 2015 John Wiley and Sons. (B) Measurement of myocardial cell movement by $\mathrm{MoS}_{2}$ transistor array with ML material. Reproduced with permission from Ref. [88]. Copyright 2020 American Chemical Society. 
$[0,0,0,0,0,0]$, 并通过软件翻译成字母 “A” . 以此类 推, 可以翻译成 $\mathrm{A} \sim \mathrm{Z}$ 的所有字母. 基于这种方式, 进 一步增加 ML 峰的个数, 可以实现对单词、短语甚至句 子等文本消息的通信加密.

在单一材料中实现多色、多时和多模发光是一个重 大挑战. 张君诚等 ${ }^{[00]}$ 通过双镧系掺杂剂的使用, 在单一 材料中实现了彩色(红、橙、黄、绿)、双时态(荧光、延 迟发光)和四模式(热/机械力响应和长/短波长)发射. 作 者同时将红色延迟发射的 $\mathrm{Pr}^{3+}$ 和绿色荧光发射的 $\mathrm{Er}^{3+}$ 掺 杂在 $\mathrm{NaNbO}_{3}$ 压电微粒中, 并最终嵌入到热塑性聚氨酯 (TPU)中, 制备了防水、柔韧、高拉伸的复合膜. 如图 $17 \mathrm{~B}$ 所示, 该复合薄膜的发光通过使用简单而通用的工 具实现了优异的多维可识别性(包括颜色、寿命和激发 模式). 在用白色的 LED 灯充电 $15 \mathrm{~s}$ 后, 室温下的复合 膜显示可见且持久的红色余辉. 在辐照后的复合膜上轻 轻书写时, 可以清楚地观察到手写痕迹的 ML 发射, 比 余辉背景强很多, 并且在光充电后显示出稳定的可恢复 性. 充能后的膜与冰 $\left(0{ }^{\circ} \mathrm{C}, \approx 1 \mathrm{~s}\right)$ 接触后, 接触区的红色 余辉消失, 用手指温度 $\left(\approx 33{ }^{\circ} \mathrm{C}, \approx 1 \mathrm{~s}\right)$ 加热, 红色余辉 重新出现; 在寒冷区域书写时, 也观察到强烈的 ML. 在 $980 \mathrm{~nm}$ 近红外激光激发下, 复合薄膜呈现亮绿色发射, 发射强度随激光能量密度的增加而增加; 当近红外激发 停止时, 绿色发射消失. 通过结合彩色荧光和红色余辉 可获得双时发射模式. 在室温下, 复合膜具有激发波长 依赖的发射. 当紫外光停止照射时, $\mathrm{Er}^{3+}$ 发出的绿色苂光 消失, 复合膜仅显示 $\operatorname{Pr}^{3+}$ 发出的红色余辉, 具有时间分辨 的发光性质，特别适合应用于先进的防伪技术.

彭慧胜等 ${ }^{[91]}$ 开发了一种新型的基于力致发光材料 的信息存储器件. 以金属掺杂的 ZnS 颗粒 PDMS 制备了
力致发光薄膜. 当器件直接受到外力刺激时, 会经历一 定程度的形变, 这些受刺激的区域可能会出现微小而不 明显的结构变化; 去除外力后, 宏观上器件可以恢复到 初始状态，同时保留了这些不可见的微观结构变化. 当 机械力如超声波进一步作用于此器件时, 从预先受到机 械刺激的位置发出明亮的光. 即该装置能够精确地记住 所经历的压力的位置, 并在不可见的情况下存储这种微 小的变化, 随后通过施加/撤去外部刺激在可见光中重 复地发光, 达到信息存储的目的. 此外, 通过对器件在 不同的图形点施加不同的应力, 可以实现用于二逻辑状 态数据存储的二进制编码芯片. 在此器件上绘制三个点 来存储机密信息, 这些信息在可见光和紫外线下肉眼不 可见. 如果亮点和弱点分别代表 “ 1 ” 和 “ 0 ”, 则在超 声时可以通过不同位置的发光得出 “ 100 ”、“ 101 ” 和 “110” 的信息. 更重要的是, 所制备的器件对外界刺激 具有快速、灵敏的响应，同时具有良好的重复性和长期 稳定性，使其在保密信息存储、防伪和安全通信等领域 具有广阔的应用前景.

\section{7 近红外成像}

相比于可见光, 近红外波长的光能更深地穿透活体 组织, 已被广泛应用于各种临床应用, 例如荧光素血管 造影、脉管系统成像和癌症监测等 ${ }^{[22]}$. 结合具有力致发 光特性的材料, 可以实现对组织内机械应力的监测 ${ }^{[93]}$.

彭明营等 ${ }^{[94]}$ 开发了一种具有近红外的弹性力致发 光特性的 $\mathrm{CaZnOS}: \mathrm{Nd}^{3+}$ 苂光粉, 发射波长在 $910 \mathrm{~nm}$ 左 右，具有良好的生物相容性(图 18). 经验证，这种近红 外发光最多可透过约 $20 \mathrm{~mm}$ 厚的猪肉组织. 之后, 作者 进行了口腔内牙齿咬伤样品的实验, 当样品没有被牙齿
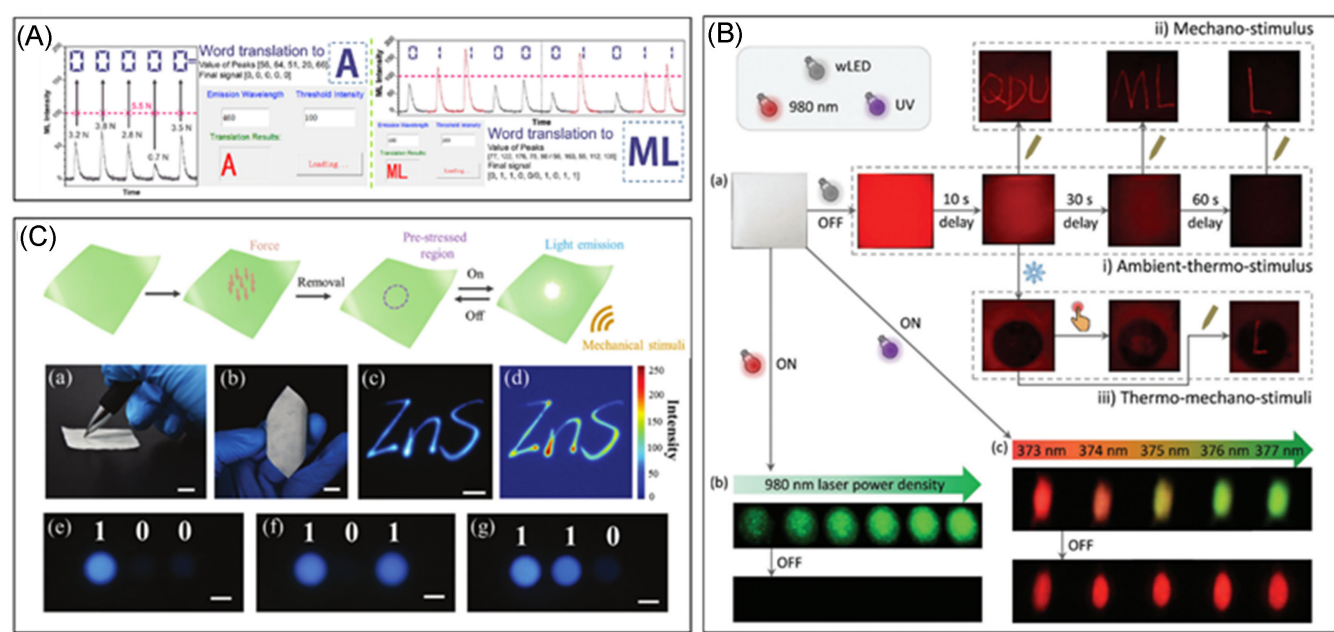

图 17 力致发光在防伪与加密方面的应用

Figure 17 Applications of mechanoluminescence materails in anti-counterfeiting and encryption (A) Information encryption. Reproduced with permission from Ref. [46]. Copyright 2020 Elsevier. (B) Anti-counterfeiting. Reproduced with permission from Ref. [90]. Copyright 2018 John Wiley and Sons. (C) Information storage. Reproduced with permission from Ref. [91]. Copyright 2019 Royal Society of Chemistry. 

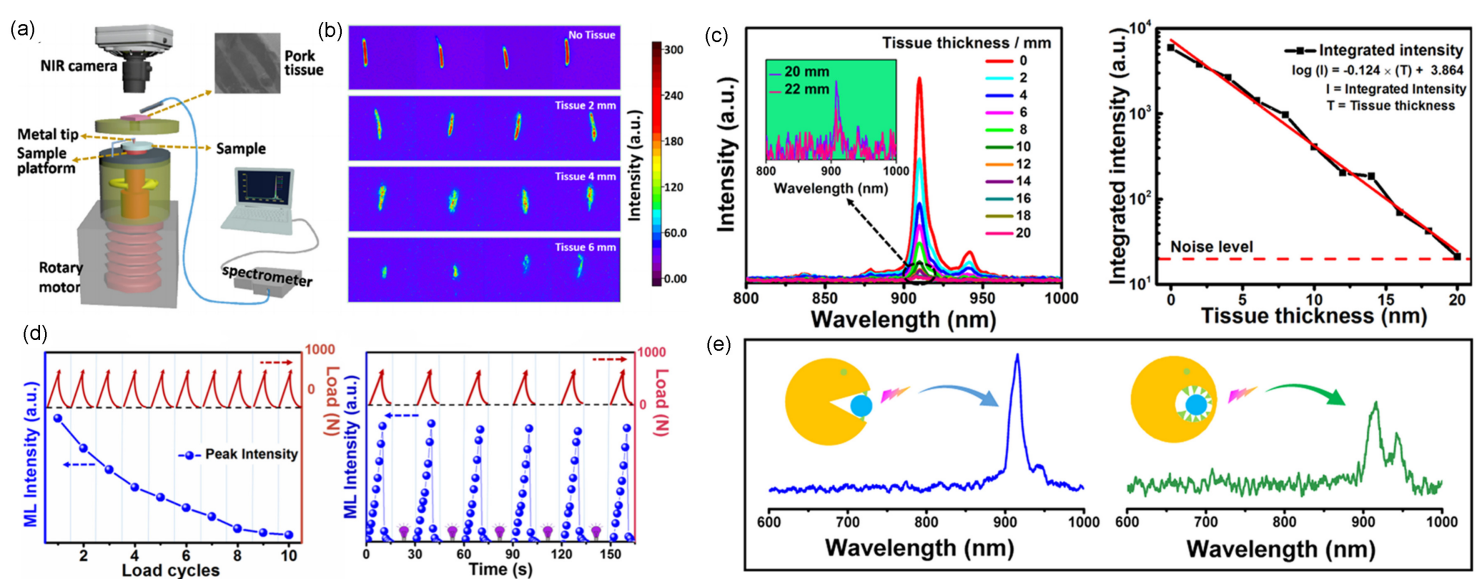

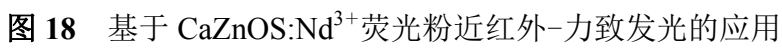

Figure 18 Applications of NIR-ML based on CaZnOS: $\mathrm{Nd}^{3+}$ phosphor

(a) Schematic diagram of detection device. (b) ML emission intensity with different thickness. (c) Relationship between thickness and ML intensity. (d) Cycle test with/without UV charging. (e) ML test in oral cavity. Reproduced with permission from Ref. [94]. Copyright 2018 American Chemical Society.

咬伤时, 不能检测到近红外光信号. 张开嘴巴咬伤样品, 可以观察到明显的 NIR-ML 信号; 闭上嘴巴后咬伤样 品, 透过唇部组织仍然可以检测到 NIR-ML 信号. 此外, 经过反复的机械应力刺激, 并在刺激后用紫外灯进行充 能, NIR-ML 强度都可以恢复, 表明这种力响应行为是 高度可重复的. 因此, 可以实时可视化地对组织中动态 力学的变化进行监测, 拓展力致发光在生物医学中的潜 在应用.

\section{6 总结与展望}

自力致发光现象有记录以来, 随着对其机理和性能 的深入研究, 科学家们已经针对不同种类的材料提出了 部分可能的机理, 比如放电、电子轰击或电子俘获-去俘 获等, 可以在一定程度上解释力致发光现象. 近年来, 越来越多具有此性质的无机、有机化合物被合成出来, 并在医疗保健、损伤检测、新型光源、防伪加密、应力 传感和可穿戴设备等方面展现出巨大的应用前景.

目前, 无机化合物, 特别是以 $\mathrm{SrAl}_{2} \mathrm{O}_{4}: \mathrm{Eu}^{2+}$ 、 $\mathrm{ZnS}: \mathrm{Mn}$ 等为代表的弹性力致发光材料以易于循环使 用、可与 PDMS 等高分子制备成复合物便于使用等优势, 成为应用最广泛的力致发光材料. 相比之下, 有机化合 物几乎都是晶体破裂导致的发光, 重复使用困难而且目 前缺乏成熟的器件制备方法, 应用上受到很大限制.

近几年, 纯有机 ML 材料取得了突破性的进展, 大 量结构新颖的有机力致发光化合物被报道, 并展现出独 特的发光性能 ${ }^{[19,95-99]}$. “MUSIC” 概念可以对聚集态下 的有机化合物的构性关系进行更好的理解, 包括力致荧 光发射 ${ }^{[100]}$ 、力致荧光磷光双重发射 ${ }^{[101]}$ 、热激活延迟苂

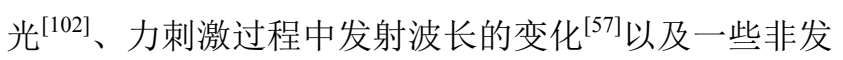
光领域 ${ }^{103]}$ 等. 这些现象的产生大多与有机分子的构型、
聚集态下分子间的堆积方式以及分子间相互作用等有 关. 更重要的是, 基于有机固体分子的 ML 的研究将拓 宽和深化对聚集态科学的认知, 促进固态发光理论的发 展 ${ }^{[19,104]}$. 目前, 有机 ML 的研究尚处于起步阶段, 其系 统理论还不完善. 相对而言, 有机力致发光材料在应用 上具有一定的优势: (1)目前的大多数有机力致发光化合 物一般只含 $\mathrm{C} 、 \mathrm{H} 、 \mathrm{O} 、 \mathrm{~N} 、 \mathrm{~S}$ 等元素, 来源广泛, 无需 上千度的高温制备, 成本较低, 适合于大批量生产; (2) 由有机分子制备的纳米颗粒已经成功应用于生物体系 中, 包括苂光、磷光成像 ${ }^{[105-108]}$ 、光动力治疗癌症 ${ }^{[109]}$ 等, 其不含重金属元素, 生物相容性相对较好, 在生物体系 的应用中具有很大的优势.

力致发光领域的研究, 也存在一些急需解决的问 题. 比如因各方面的限制, 许多报道中只提到发现了新 的 ML 现象, 缺少这种现象产生的根本原因. 由于研磨、 刮擦、按压、碰撞等多种机械力都能产生力致发光现象, 对于施加力的精确测试没有统一的标准, 产生的发光强 度也没有精确的标准和定量的描述, 难以对不同实验室 的测试结果进行有效的对比.

总而言之, 目前有机力致发光仍处于研究的起步阶 段, 其独特的性能和潜在的应用前景吸引了国内外科学 家的广泛关注, 有望通过后续的研究系统地分析其内在 机制，并实现其在应力传感、结构损伤检测、防伪加密以 及医疗保健等方面的应用和拓展. 同时，这类材料的深 入研究, 也可以促进发光机理的深入理解和拓展 ${ }^{[110-111]}$.

\section{References}

[1] (a) Bacon, F. The Advancement of Learning, Press of P. F Collier \& Son, New York, 1901, pp. 208 209 .

(b) Feng, A.; Smet, A. P. F. Materials 2018, 11, 484.

[2] Xie, Y.; Li, Z. Chem 2018, 4, 943.

[3] Sakai, K.; Koga, T.; Imai, Y.; Maehara, S.; Xu, C. N. Phys. Chem. 
Chem. Phys. 2006, 8, 2819.

[4] Lavrov, A. Strain 2005, 41, 135.

[5] Zhang, J.-C.; Wang, X.; Marriott, G.; Xu, C.-N. Prog. Mater. Sci. 2019, 103, 678 .

[6] Chandra, B. P.; Rathore, A. S. Cryst. Res. Technol. 1995, 30, 885.

[7] Bünzli, J.-C. G.; Wong, K.-L. J. Rare Earths 2018, 36, 1.

[8] Zhang, H.; Wei, Y.; Huang, X.; Huang, W. J. Lumin. 2019, 207, 137

[9] Chandra, B. P.; Chandra, V. K.; Jha, P.; Patel, R.; Shende, S. K.; Thaker, S.; Baghel, R. N. J. Lumin. 2012, 132, 2012.

[10] Chandra, B. P.; Chandra, V. K.; Jha, P. J. Lumin. 2013, 135, 139.

[11] Luo, J.; Xie, Z.; Lam, J. W.; Cheng, L.; Chen, H.; Qiu, C.; Kwok, H. S.; Zhan, X.; Liu, Y.; Zhu, D.; Tang, B. Z. Chem. Commun. 2001, 1740 .

[12] Dang, Q.; Hu, L.; Wang, J.; Zhang, Q.; Han, M.; Luo, S.; Gong, Y.; Wang, C.; Li, Q.; Li, Z. Chem.-Eur. J. 2019, 25, 7031.

[13] Liu, F.; Tu, Z.; Fan, Y.; Li, Q.; Li, Z. ACS Omega 2019, 4, 18609.

[14] Li, W.; Huang, Q.; Mao, Z.; Li, Q.; Jiang, L.; Xie, Z.; Xu, R.; Yang, Z.; Zhao, J.; Yu, T.; Zhang, Y.; Aldred, M. P.; Chi, Z. Angew. Chem., Int. Ed. 2018, 57, 12727.

[15] Wang, J.; Chai, Z.; Wang, J.; Wang, C.; Han, M.; Liao, Q.; Huang, A.; Lin, P.; Li, C.; Li, Q.; Li, Z. Angew. Chem., Int. Ed. 2019, 58, 17297.

[16] Yan, C.; Yang, F.; Wu, M.; Yuan, Y.; Chen, F.; Chen, Y. Macromolecules 2019, 52, 9376.

[17] Yuan, Y.; Yuan, W.; Chen, Y. Sci. China Mater. 2016, 59, 507.

[18] Chakravarty, A.; Phillipson, T. E. J. Phys. D: Appl. Phys. 2004, 37, 2175.

[19] Xie, Y.; Li, Z. Mater. Chem. Front. 2020, 4, 317

[20] Li, Q.; Li, Z. Acc. Chem. Res. 2020, 53, 962.

[21] Chandra, B. P.; Chandra, V. K.; Jha, P. Phys. B 2015, 463, 62.

[22] Zhang, J.-C.; Long, Y.-Z.; Yan, X.; Wang, X.; Wang, F. Chem. Mater. 2016, 28, 4052 .

[23] Wang, X.; Xu, C. N.; Yamada, H.; Nishikubo, K.; Zheng, X. G. Adv Mater. 2005, 17, 1254.

[24] Chandra, B. P.; Bagri, A. K.; Chandra, V. K. J. Lumin. 2010, 130, 309

[25] Li, Q.; Tang, Y.; Hu, W.; Li, Z. Small 2018, 14, 1801560.

[26] Li, Q. Q.; Li, Z. Sci. China Mater. 2020, 63, 177.

[27] Wang, Y.; Yang, J.; Tian, Y.; Fang,M.; Liao, Q.; Wang, L.; Hu, W.; Tang, B. Z.; Li, Z. Chem. Sci. 2020, 11, 833.

[28] Tian, Y.; Gong, Y.; Liao, Q.; Wang, Y.; Ren, J.; Fang, M.; Yang, J.; Li, Z. Cell Rep. Phys. Sci. 2020, 1, 100052.

[29] Liu, F.; Wu, F.; Ling, W.; Tu, Z.; Zhang, J.; Wei, Z.; Zhu, L.; Li, Q.; Li, Z. ACS Energy Lett. 2019, 4, 2514.

[30] Tu, J.; Liu, C.; Fan, Y.; Liu, F.; Chang, K.; Xu, Z.; Li, Q.; Chen, Y.; Li, Z. J. Mater. Chem. A 2019, 7, 15662.

[31] Xie, Y.; Gong, Y.; Han, M.; Zhang, F.; Peng, Q.; Xie, G.; Li, Z. Macromolecules 2019, 52, 896.

[32] Li, Y.; Han, M.; Yang, W.; Guo, J.; Chang, K.; Wang, J.; Min, J.; Li, Q.; Li, Z. Mater. Chem. Front. 2019, 3, 1840.

[33] Zink, J. I.; Hardy, G. E.; Sutton, J. E. J. Phys. Chem. 1976, 80, 248.

[34] Tu, J.; Fan, Y.; Wang, J.; Li, X.; Liu, F.; Han, M.; Wang, C.; Li, Q.; Li, Z. J. Mater. Chem. C 2019, 7, 12256.

[35] Fang, M.; Yang, J.; Liao, Q.; Gong, Y.; Xie, Z.; Chi, Z.; Peng, Q.; Li, Q.; Li, Z. J. Mater. Chem. C 2017, 5, 9879

[36] Xie, Y.; Tu, J.; Zhang, T.; Wang, J.; Xie, Z.; Chi, Z.; Peng, Q.; Li, Z. Chem. Commun. 2017, 53, 11330.

[37] Liu, F.; Tu, J.; Wang, X.; Wang, J.; Gong, Y.; Han, M.; Dang, X.; Liao, Q.; Peng, Q.; Li, Q.; Li, Z. Chem. Commun. 2018, 54, 5598

[38] Huang, G.; Jiang, Y.; Wang, J.; Li, Z.; Li, B. S.; Tang, B. Z. J. Mater. Chem. C 2019, 7, 12709

[39] Wang, C.; Yu, Y.; Chai, Z.; He, F.; Wu, C.; Gong, Y.; Han, M.; Li, Q.; Li, Z. Mater. Chem. Front. 2019, 3, 32.

[40] Gong, Y.; Zhang, P.; Gu, Y.; Wang, J.; Han, M.; Chen, C.; Zhan, X.; Xie, Z.; Zou, B.; Peng, Q.; Chi, Z.; Li, Z. Adv. Opt. Mater. 2018, 6, 1800198.

[41] Mu, Y.; Yang, Z.; Chen, J.; Yang, Z.; Li, W.; Tan, X.; Mao, Z.; Yu,
T.; Zhao, J.; Zheng, S.; Liu, S.; Zhang, Y.; Chi, Z.; Xu, J.; Aldred, M. P. Chem. Sci. 2018, 9, 3782 .

[42] Li, W.; Huang, Q.; Mao, Z.; Zhao, J.; Wu, H.; Chen, J.; Yang, Z.; Li, Y.; Yang, Z.; Zhang, Y.; Aldred, M. P.; Chi, Z. Angew. Chem., Int. Ed. 2020, 59, 3739

[43] Yu, Y.; Wang, C.; Wei, Y.; Fan, Y.; Yang, J.; Wang, J.; Han, M.; Li, Q.; Li, Z. Adv. Optical Mater. 2019, 7. 1900505.

[44] Tu, J.; Liu, F.; Wang, J.; Li, X.; Gong, Y.; Fan, Y.; Han, M.; Li, Q.; Li, Z. ChemPhotoChem 2019, 3, 133.

[45] Yu, Y.; Fan, Y.; Wang, C.; Wei, Y.; Liao, Q.; Li, Q.; Li, Z. J. Mater. Chem. C 2019, 7, 13759.

[46] Wang, C.; Yu, Y.; Yuan, Y.; Ren, C.; Liao, Q.; Wang, J.; Chai, Z.; Li, Q.; Li, Z. Matter 2020, 2, 181.

[47] Fontenot, R. S.; Hollerman, W. A.; Aggarwal, M. D.; Bhat, K. N.; Goedeke, S. M. Measurement 2012, 45, 431.

[48] Hollerman, W. A.; Fontenot, R. S.; Bhat, K. N.; Aggarwal, M. D.; Guidry, C. J.; Nguyen, K. M. Opt. Mater. 2012, 34, 1517.

[49] Zhang, J.-C.; Xu, C.-N.; Wang, X.; Long, Y.-Z. Chem. Mater. 2014, $28,4052$.

[50] Terasaki, N.; Xu, C.-N. J. Colloid Interf. Sci. 2014, 427, 62.

[51] Zhang, J.-C.; Xu, C.-N.; Kamimura, S.; Terasawa, Y.; Yamada, H.; Wang, X. Opt. Express 2013, 21, 12976.

[52] Yang, J.; Ren, Z.; Xie, Z.; Liu, Y.; Wang, C.; Xie, Y.; Peng, Q.; Xu, B.; Tian, W.; Zhang, F.; Chi, Z.; Li, Q.; Li, Z. Angew. Chem., Int. Ed. 2017, 56, 880

[53] Chen, Y.; Xu, C.; Xu, B.; Mao, Z.; Li, J.-A.; Yang, Z.; Peethani, N. R.; Liu, C.; Shi, G.; Gu, F. L.; Zhang, Y.; Chi, Z. Mater. Chem. Front. 2019, 3, 1800 .

[54] Xiong, P.; Peng, M.; Cao, J.; Li, X. J. Am. Ceram. Soc. 2019, 102, 5899.

[55] Xie, Z.; Yu, T.; Chen, J.; Ubba, E.; Wang, L.; Mao, Z.; Su, T.; Zhang, Y.; Aldred, M. P.; Chi, Z. Chem. Sci. 2018, 9, 5787.

[56] Sun, Q.; Zhang, K.; Zhang, Z.; Tang, L.; Xie, Z.; Chi, Z.; Xue, S.; Zhang, H.; Yang, W. Chem. Commun. 2018, 54, 8206.

[57] Yang, J.; Qin, J.; Geng, P.; Wang, J.; Fang, M.; Li, Z. Angew. Chem., Int. Ed. 2018, 57, 14174.

[58] Yang, J.; Fang, M.; Li, Z. InfoMat 2020, 2, 791.

[59] Wang, J.; Wang, C.; Gong, Y.; Liao, Q.; Han, M.; Jiang, T.; Dang, Q.; Li, Y.; Li, Q.; Li, Z. Angew. Chem., Int. Ed. 2018, 57, 16821.

[60] Jeong, S. M.; Song, S.; Lee, S. K.; Ha, N. Y. Adv. Mater. 2013, 25 , 6194.

[61] Peng, D.; Chen, B.; Wang, F. Chempluschem 2015, 80, 1209.

[62] Kim, Y.; Kim, J. S.; Kim, G. W. Sci. Rep. 2018, 8, 12023.

[63] Kim, Y.; Roy, S.; Jung, G. Y.; Oh, J. S.; Kim, G. W. Sci. Rep. 2019, 9, 15215.

[64] Jiang, Y.; Wang, F.; Zhou, H.; Fan, Z.; Wu, C.; Zhang, J.; Liu, B.; Wang, Z. Mater. Sci. Eng. C 2018, 92, 374.

[65] Wu, X.; Zhu, X.; Chong, P.; Liu, J.; Andre, L. N.; Ong, K. S.; Brinson, K., Jr.; Mahdi, A. I.; Li, J.; Fenno, L. E.; Wang, H.; Hong, G. PNAS 2019, 116, 26332.

[66] Yoshida, A.; Liu, L.; Tu, D.; Kainuma, S.; Xu, C.-N. J. Disaster Res. 2017, 12, 506

[67] Terasaki, N. Sens. Mater. 2016, 28, 827.

[68] Xu, H.; Wang, F.; Wang, Z.; Zhou, H.; Zhang, G.; Zhang, J.; Wang, J.; Yang, S. Tribol. Lett. 2019, 67, 13.

[69] Terasaki, N.; Xu, C.-N. IEEE Sens. J. 2013, 13, 3999.

[70] Shin, S. W.; Oh, J. P.; Hong, C. W.; Kim, E. M.; Woo, J. J.; Heo, G. S.; Kim, J. H. ACS Appl. Mater. Interfaces 2016, 8, 1098.

[71] Jeong, S. M.; Song, S.; Kim, H.; Joo, K.-I.; Takezoe, H. Adv. Funct. Mater. 2016, 26, 4848 .

[72] Jeong, S. M.; Song, S.; Kim, H. Nano Energy 2016, 21, 154

[73] Jeong, S. M.; Song, S.; Joo, K.-I.; Kim, J.; Hwang, S.-H.; Jeong, J.; Kim, H. Energy Environ. Sci. 2014, 7, 3338.

[74] Wong, M. C.; Chen, L.; Tsang, M. K.; Zhang, Y.; Hao, J. Adv. Mater. 2015, 27, 4488 .

[75] Terasaki, N.; Xu, C.-N.; Imai, Y.; Yamada, H. Jpn. J. Appl. Phys. 2007, 46, 2385.

[76] Patel, D. K.; Cohen, B.-E.; Etgar, L.; Magdassi, S. Mater. Horiz. 
2018, 5, 708.

[77] Lynch, J. P.; Pulliam, E.; Hoover, G.; Tiparti, D.; Ryu, D. Development of self-powered strain sensor using mechano-luminescent $\mathrm{ZnS}: \mathrm{Cu}$ and mechano-optoelectronic P3HT. In Sensors and Smart Structures Technologies for Civil, Mechanical, and Aerospace Systems 2017, 2017 (DOI: 10.1117/12.2260318).

[78] Kwon, S.; Hwang, Y. H.; Nam, M.; Chae, H.; Lee, H. S.; Jeon, Y.; Lee, S.; Kim, C. Y.; Choi, S.; Jeong, E. G.; Choi, K. C. Adv. Mater. 2020, 32, 1903488.

[79] Shrivastava, S.; Trung, T. Q.; Lee, N. E. Chem. Soc. Rev. 2020, 49, 1812.

[80] Jeong, S. M.; Song, S.; Seo, H.-J.; Choi, W. M.; Hwang, S.-H.; Lee, S. G.; Lim, S. K. Adv. Sustainable Syst. 2017, 1, 1700126.

[81] Qian, X.; Cai, Z.; Su, M.; Li, F.; Fang, W.; Li, Y.; Zhou, X.; Li, Q.; Feng, X.; Li, W.; Hu, X.; Wang, X.; Pan, C.; Song, Y. Adv. Mater. 2018, 30, 1800291.

[82] Park, H. J.; Kim, S.; Lee, J. H.; Kim, H. T.; Seung, W.; Son, Y.; Kim, T. Y.; Khan, U.; Park, N. M.; Kim, S. W. ACS Appl. Mater. Interfaces 2019, 11, 5200.

[83] Zhang, J.; Bao, L.; Lou, H.; Deng, J.; Chen, A.; Hu, Y.; Zhang, Z.; Sun, X.; Peng, H. J. Mater. Chem. C 2017, 5, 8027.

[84] Liang, G.; Ruan, Z.; Liu, Z.; Li, H.; Wang, Z.; Tang, Z.; Mo, F.; Yang, Q.; Ma, L.; Wang, D.; Zhi, C. Adv. Electron. Mater. 2019, 5. 1900553 .

[85] Monette, Z.; Kasar, A. K.; Menezes, P. L. J. Mater. Sci.-Mater. Electron. 2019, 30, 19675.

[86] Wang, X.; Que, M.; Chen, M.; Han, X.; Li, X.; Pan, C.; Wang, Z. L. Adv. Mater. 2017, 29, 1605817.

[87] Wang, X.; Zhang, H.; Yu, R.; Dong, L.; Peng, D.; Zhang, A.; Zhang, Y.; Liu, H.; Pan, C.; Wang, Z. L. Adv. Mater. 2015, 27, 2324 .

[88] Jang, J.; Kim, H.; Ji, S.; Kim, H. J.; Kang, M. S.; Kim, T. S.; Won, J. E.; Lee, J. H.; Cheon, J.; Kang, K.; Im, W. B.; Park, J. U. Nano Lett. 2020, 20, 66 .

[89] Arppe, R.; Sørensen, T. J. Nat. Rev. Chem. 2017, 1, 0031.

[90] Zhang, J. C.; Pan, C.; Zhu, Y. F.; Zhao, L. Z.; He, H. W.; Liu, X.; Qiu, J. Adv. Mater. 2018, 30, 1804644

[91] Zuo, Y.; Xu, X.; Tao, X.; Shi, X.; Zhou, X.; Gao, Z.; Sun, X.; Peng, H. J. Mater. Chem. C 2019, 7, 4020.
[92] Kenry; Duan, Y.; Liu, B. Adv. Mater. 2018, 30, 1802394.

[93] Xiong, P.; Peng, M. J. Mater. Chem. C 2019, 7, 6301.

[94] Li, L.; Wondraczek, L.; Li, L.; Zhang, Y.; Zhu, Y.; Peng, M.; Mao, C. ACS Appl. Mater. Interfaces 2018, 10, 14509.

[95] Gong, Y.; He, S.; Li, Y.; Li, Z.; Liao, Q.; Gu, Y.; Wang, J.; Zou, B.; Li, Q.; Li, Z. Adv. Opt. Mater. 2020, 8, 1902036.

[96] Li, J. A.; Zhou, J.; Mao, Z.; Xie, Z.; Yang, Z.; Xu, B.; Liu, C.; Chen, X.; Ren, D.; Pan, H.; Shi, G.; Zhang, Y.; Chi, Z. Angew. Chem., Int. Ed. 2018, 57, 6449.

[97] Mukherjee, S.; Thilagar, P. Angew. Chem., Int. Ed. 2019, 58, 7922.

[98] Ubba, E.; Tao, Y.; Yang, Z.; Zhao, J.; Wang, L.; Chi, Z. Chem.Asian. J. 2018, 13, 3106.

[99] Li, Q.; Li, Z. Adv. Sci. 2017, 4, 1600484.

[100] Wang, C.; Xu, B.; Li, M.; Chi, Z.; Xie, Y.; Li, Q.; Li, Z. Mater. Horiz. 2016, 3, 220.

[101] Yang, J.; Gao, X.; Xie, Z.; Gong, Y.; Fang, M.; Peng, Q.; Chi, Z.; Li, Z. Angew. Chem., Int. Ed. 2017, 56, 15299.

[102] Xu, S.; Liu, T.; Mu, Y.; Wang, Y. F.; Chi, Z.; Lo, C. C.; Liu, S.; Zhang, Y.; Lien, A.; Xu, J. Angew. Chem., Int. Ed. 2015, 54, 874.

[103] Liu, F.; Bi, S.; Wang, X.; Leng, X.; Han, M.; Xue, B.; Li, Q.; Zhou, H.; Li, Z. Sci. China: Chem. 2019, 62, 739.

[104] Yang, J.; Chi, Z.; Zhu, W.; Tang, B.; Li, Z. Sci. China: Chem. 2019, 62, 1090.

[105] Liao, Q.; Gao, Q.; Wang, J.; Gong, Y.; Peng, Q.; Tian, Y.; Fan, Y.; Guo, H.; Ding, D.; Li, Q.; Li, Z. Angew. Chem., Int. Ed. 2020, 59, 9946.

[106] Song, Y.; Xu, L.; Wu, Q.; Xiao, S.; Zeng, H.; Gong, Y.; Li, C.; Cheng, S.; Li, Q.; Zhang, L.; Li, Z. Small Methods 2020, 4 1900779.

[107] Zong, L.; Zhang, H.; Li, Y.; Gong, Y.; Li, D.; Wang, J.; Wang, Z.; Xie, Y.; Han, M.; Peng, Q.; Li, X.; Dong, J.; Qian, J.; Li, Q.; Li, Z. ACS Nano 2018, 12, 9532.

[108] Yang, J.; Li, Z. Chin. J. Org. Chem. 2019, 39, 3304 (in Chinese). (杨杰, 李振, 有机化学, 2019, 39, 3304.)

[109] Zhou, Z.; Song, J.; Nie, L.; Chen, X. Chem. Soc. Rev. 2016, 45, 6597.

[110] Fang, M.; Yang, J.; Li. Z. Chin. J. Polym. Sci. 2019, 37, 383.

[111] Yang, J.; Zhen, X.; Wang, B.; Gao, X.; Ren, Z.; Wang, J.; Xie, Y.; Li, J.; Peng, Q.; Pu, K.; Li. Z. Nat. Commun. 2018, 9, 840.

(Zhao, C.) 